\title{
Understanding ambiguous words in sentence contexts: electrophysiological evidence for delayed contextual selection in Broca's aphasia
}

\author{
TAMARA Y. SWAAB, $*$ COLIN BROWN $\uparrow$ and PETER HAGOORT $\dagger$ \\ * Center for Neuroscience, University of California, Davis, U.S.A.; $†$ Max Planck Institute for Psycholinguistics, Nijmegen, \\ The Netherlands
}

(Received 13 February 1997; accepted 6 December 1997)

\begin{abstract}
This study investigates whether spoken sentence comprehension deficits in Broca's aphasics results from their inability to access the subordinate meaning of ambiguous words (e.g. bank), or alternatively, from a delay in their selection of the contextually appropriate meaning. Twelve Broca's aphasics and twelve elderly controls were presented with lexical ambiguities in three context conditions, each followed by the same target words. In the concordant condition, the sentence context biased the meaning of the sentence-final ambiguous word that was related to the target. In the discordant condition, the sentence context biased the meaning of the sentence-final ambiguous word that was incompatible with the target. In the unrelated condition, the sentence-final word was unambiguous and unrelated to the target. The task of the subjects was to listen attentively to the stimuli. The activational status of the ambiguous sentence-final words was inferred from the amplitude of the N400 to the targets at two inter-stimulus intervals (ISIs) $(100 \mathrm{~ms}$ and $1250 \mathrm{~ms})$. At the short ISI, the Broca's aphasics showed clear evidence of activation of the subordinate meaning. In contrast to elderly controls, however, the Broca's aphasics were not successful at selecting the appropriate meaning of the ambiguity in the short ISI version of the experiment. But at the long ISI, in accordance with the performance of the elderly controls, the patients were able to successfully complete the contextual selection process. These results indicate that Broca's aphasics are delayed in the process of contextual selection. It is argued that this finding of delayed selection is compatible with the idea that comprehension deficits in Broca's aphasia result from a delay in the process of integrating lexical information. (C) 1998 Elsevier Science Ltd. All rights reserved.
\end{abstract}

Key Words: Lexical ambiguity resolution; Broca's aphasia; processing deficits; delayed lexical integration; N400; ERPs.

Broca's aphasia has been reliably associated with syntactic comprehension deficits $[3,8,9,29,45,83]$. More recent studies have shown that these patients may have lexical-semantic comprehension deficits as well [53, 54], although this only shows up under a restricted set of circumstances $[32,33]$. The nature of the deficits that underlie comprehension problems in Broca's aphasia is still a matter of debate. Traditionally, comprehension deficits in these patients have been attributed to losses of stored linguistic representations [9, 25, 82]. However, in recent years an increasing number of studies have reported results that are suggestive of processing impairments, rather than a loss of knowledge [3, 6, 20, 30, 32,

$\$$ To whom all correspondence should be addressed: Tamara Swaab, Ph.D., Department of Neurology and Center for Neuroscience, University of California, 1544 Newton Ct., Davis CA, 95616, U.S.A. Tel.: (530)-757-8870; Fax: (530)-757-8827; E-mail: swaab@marzen.ucdavis.edu
$33,36,46,53,54,70,77,83]$. Processing impairments in Broca's aphasia have been related to an impairment in automatically accessing and/or activating the knowledge representations in the mental lexicon [54, 73]. Alternatively, it has been proposed that rather than lexical access, the integration of lexical information into the preceding word or sentence context is impaired in these patients $[6,32,33,36,70,77]$. More specifically, Hagoort et al. [31-33, 36] suggest that certain aphasic comprehension deficits result from a delay in the integration of lexical information.

In the present study we tested the idea that aphasic comprehension problems in Broca's aphasia are due to a delay in lexical integration by examining the time course of ambiguity resolution in sentence context, focusing on the selection of the appropriate meaning of ambiguous words on the basis of sentential context information. Ambiguous words like, for example, bank have the same form representation but two (or more) unrelated mean- 
ings, as is illustrated in the following example: (1) The poor man made a phone call to the bank; (2) The tall man planted a tree on the bank. Sentence one clearly biases the money meaning of this word, whereas sentence two biases the alternative meaning. If a listener is confronted with the word bank in a sentence context, unique selection of the appropriate meaning of this word is dependent upon its integration into the context. Rapid lexical integration is therefore crucial to the selection of the appropriate meaning of ambiguous words in sentence contexts. Thus, if comprehension deficits in Broca's aphasia are due to a delay in the time course of lexical integration, this will be evident from a delay in the selection of the contextually appropriate meaning.

\section{Ambiguity resolution in sentence context}

In studies of normal language comprehension, ambiguous words (e.g. bank) have been used as a tool to discriminate between modular and interactive theories of the language comprehension system $[13,15,17,24,31$, $34,52,58,62,63,67-69,72,76,78]$. Most of the studies on ambiguity resolution have asked the following question: To what extent does the higher order context representation influence the recognition of a word? The answer to this question is still a matter of debate. Evidence has been obtained for both context-independent (or modular) and context-dependent (or interactive) views. In support of the context independent models is the finding that both meanings of ambiguous words are activated, irrespective of sentence context [13, 58, 72], or that regardless of context the most frequent meaning of the ambiguity is accessed first [37, 62, 74, 75, 76]. Other studies have found activation for only the contextually appropriate meaning $[24,56,68]$, providing evidence for the context dependent view. Most recent studies, however, indicate that the type of context and the relative frequency of the ambiguous words (dominant vs subordinate) is of influence on the pattern of results. Multiple access modulated by frequency is found when the sentence context is not too constraining [62]. If the context contains words that are associatively related to one of the meanings of the ambiguous word, this meaning is activated or selected more rapidly [66]. And finally, if the context strongly biases toward the dominant meaning of the lexical ambiguity by priming a salient feature of this meaning, then the subordinate meaning may not be accessed at all $[74,75]$. In contrast, the dominant meaning seems always to be accessed, even in contexts that strongly bias the subordinate meaning.

Ambiguity resolution in sentence context: studies in aphasia. Ambiguity resolution in sentence contexts has also been studied in aphasic patients. The aim of these studies was to investigate whether aphasic patients are able to access both the dominant and the subordinate meanings of ambiguous words and/or whether the time course of the activation/selection processes were slowed.
Using a cross-modal lexical decision paradigm, Swinney et al. [73] showed that Broca's aphasics, in contrast to normal control subjects and Wernicke's aphasics, had faster reaction times (RTs) only to target words that were related to the most frequent meaning of ambiguous words. This was true even when the preceding sentence context biased the alternative, less frequent, meaning. They concluded from this study that Broca's aphasics either fail to exhaustively access word meanings (i.e. they cannot access the subordinate meaning), or alternatively, that "the lexical module operates on a slower-thannormal rise time" in these patients. Because Swinney et al. [73] presented the visual target at only one interstimulus interval (ISI), namely at the offset of the auditorily presented ambiguous word, they were not able to distinguish between these two hypotheses.

The second hypothesis (rise-time hypothesis) that was proposed by Swinney et al. [73] was investigated by Prather et al. [61]. They used an ISI of $1500 \mathrm{~ms}$ between the ambiguous word and the target, and also used a cross modal paradigm. In their study, the sentence context always biased the dominant meaning of the ambiguous word and they found no evidence for the activation of the infrequent meaning in five Broca's aphasics. However, given the results in normal young subjects $[58,66$, 72] no activation of the subordinate meaning was to be expected. This is because when the sentence context biases the dominant meaning of the ambiguous words, a time interval of $1500 \mathrm{~ms}$ is more than sufficient to complete the contextual selection process, which means that the dominant meaning has been integrated and the subordinate meaning has decayed or has been suppressed. Therefore, the Prather et al. [61] results are inconclusive with respect to the activation of the infrequent meaning of ambiguous words.

Based on studies that varied the interval of silence between ambiguity and target word, with ambiguous words presented in different kinds of biasing sentential contexts, Hagoort [31] argued that Broca's aphasics are able to access both the dominant and the subordinate meanings of ambiguous words, but that they are delayed in using the sentence context to select the contextually appropriate meaning. Hagoort [31] proposed that this delay in contextual selection was due to a delay in the integration of lexical meanings into an overall message representation of the preceding sentence context.

\section{Event-related potentials (ERPS)}

In the present study, we used ERPs to further investigate the time course of the selection of lexically ambiguous words in Broca's aphasia. ERPs reflect the summation of synchronous post-synaptic activity of a large population of neurons engaged in information processing [1]. ERPs can be distinguished from the background electrical activity of the brain by making a time-locked average over several stimulus events. The resultant ERP 
will typically include a number of positive and negative voltage peaks that appear at specific latencies and that have specific distributions over the scalp. Of particular importance for aphasia research is that ERPs can be measured without the need for an overt, potentially interfering response. This makes it possible to test aphasic patients with severe comprehension deficits, who would be more difficult to test in behavioral paradigms that require a task. In addition and important for the purposes of the present study, ERPs provide a millisecond-level temporal resolution of neural activity underlying language processes. Thus, they do not only allow inferences about the types of linguistic information that these patients are (in)sensitive to, but also about possible changes in the time course of the relevant processing events.

One particular ERP component, the N400, has been shown to be sensitive to semantic aspects of the linguistic input $[50,60]$. The N400 is a negative deflection in the ERP waveform that is maximal over centro-posterior electrode sites and reaches its peak amplitude between 250-600 ms after stimulus onset [48]. This component was first reported by Kutas and Hillyard [47], who found that the N400 to anomalous sentence endings ("He spread the warm bread with socks") was larger in amplitude than the N400 to semantically congruent sentence endings ("It was his first day at work"). This difference in the amplitude of the N400 is referred to as the N400 effect. In contrast to semantic anomalies, physically deviant words (e.g. printed in bold-face type) elicited a positive potential rather than a negativity. Other nonsemantic deviations such as musical or grammatical violations also failed to elicit the N400 effect $[4,19,21$, $35,48,55,59]$.

Modulations of the N400 amplitude are not restricted to semantic violations. Word expectancy and position of the word in the sentence are other factors that modulate the amplitude of the N400 [49, 79, 80]. Kutas et al. [49] observed that the N400 amplitude is inversely related to cloze probability: A larger N400 is obtained when a word is less expected given the sentence context. Van Petten and Kutas [80] found that the N400 to open class words was larger at the beginning of the sentence than to those at the end of the sentence. They also observed an interaction on N400 amplitude between word frequency and ordinal position of the open class words in the sentences: The frequency effect was only observed for the words at the beginning of the sentence [79].

With respect to the processing nature of the N400, there is evidence that in the context of a sentence or a word, the modulation of the N400 amplitude is dependent upon the ease or difficulty with which a word can be integrated into the preceding context $[5,11,12,38,41$, 64]. Its amplitude is larger to words that are difficult to integrate and reduced to words that are easily integrated into a higher order representation of the preceding context.

The findings of a recent ERP study support the idea that comprehension deficits in aphasia result from a delay in the integration of lexical information [70]. In this study, subjects were asked to listen attentively to sentences that were spoken at a normal rate. In half of the sentences, the meaning of the sentence-final word was anomalous with respect to the preceding sentence context and in the other half of the sentences the sentence-final word matched the semantic specifications of the preceding sentence context. The N400 was measured to the sentencefinal words in both conditions. The normal control subjects in this study showed the typical N400 effect [47], that is a reduction of the N400 amplitude to sentence-final congruent words relative to the N400 to sentence-final anomalous words. This N400 effect reflects that in the congruent condition the sentence-final word was easy to integrate into the preceding sentence context, while this was not the case in the anomalous condition. The results for the aphasic patients were analysed according to the severity of their comprehension deficit, irrespective of their syndrome classification (Broca vs Wernicke). The results showed that in contrast to the normal controls, the low comprehenders had a smaller and clearly delayed N400 effect, while the high comprehenders showed an N400 effect that was comparable to the neurologically unimpaired controls. The delay in the N400 effect for the low comprehenders in this study is compatible with the idea that these patients are slower than normal in the process of integrating lexical information into the overall message representation of the whole utterance.

\section{The present study}

In the present study, the possibility that comprehension problems in Broca's aphasia are due to a delay in the integration of lexical meanings into an overall message representation was further tested by investigating the time course of ambiguity resolution in sentence context. Subjects were presented with sentences in three context conditions, followed by a target word. This is illustrated in the following example. The target word was RIVER in all three conditions: (1) Concordant: The man planted a tree on the bank; (2) Discordant: The man made a phone call to the bank; (3) Unrelated: The boy petted the dog on its head. In the concordant condition, the target was related to the meaning of the sentence-final ambiguous word that was biased by the sentence context. In the discordant condition, the sentence biased the alternative meaning of the sentence-final ambiguous word. This meaning was unrelated to the target. Finally in the unrelated condition, the sentence ended in an unambiguous word that was unrelated to the target.

Instead of measuring RTs to target words in a lexical decision experiment $[31,73]$, in the present study subjects were asked to listen attentively to the sentences and the target words that follow them, while their EEG was recorded. The major focus of the experiment was on changes in the amplitude of the N400 to the auditorily presented 
target words. The target words were always related to the subordinate or less frequent meaning of the ambiguous words. This was done because Swinney et al. [73] and Prather et al. [61] have suggested that Broca's aphasics have a selective deficit in processing the subordinate meaning of ambiguous words. The ISI between the offset of the sentence-final word and the onset of the target was varied in two versions of the experiment. In the short version the ISI was $100 \mathrm{~ms}$ and in the long version it was $1250 \mathrm{~ms}$. The pattern of results for Broca's aphasics was compared to a group of neurologically unimpaired elderly controls. The same subject groups were tested in the two ISI versions. This made within-subject comparisons of the N400 effects in the different context conditions for the two ISI versions possible. Under such circumstances, changes in the N400 amplitude between the two ISI versions in aphasic patients would be attributable to their aphasia, and not to an overall reduction of N400 amplitude as an aspecific result of their brain damage.

Based on the results from Hagoort [31], the elderly controls were expected to have selected the appropriate meaning of the ambiguous words in both the short and the long ISI version of the experiment. This means that they have quickly matched both meanings of the ambiguous word against the sentence context, that they have successfully integrated the contextually appropriate meaning of the ambiguous word and that the contextually inappropriate meaning has either decayed or has been suppressed. If this is the case, we should find a reduction of the N400 to the targets in the concordant relative to the unrelated and the discordant conditions, but no reduction of the amplitude of the N400 to the targets in the discordant relative to the unrelated condition.

Dependent upon their deficit, different patterns of results could be expected for the aphasic patients. If Broca's aphasics are unable to access the subordinate meaning of ambiguous words [73], then no reduction of the N400 amplitude to targets in the concordant relative to the unrelated condition should occur at either of the ISIs. However, if the activation of the subordinate meanings of ambiguous words has a slower-than-normal rise time in these patients [73], then the N400 amplitude to targets in the concordant condition might only be reduced relative to the unrelated condition in the long ISI version. Alternatively, if these patients are delayed in the process of contextual selection [31], then there may be evidence of activation of the contextually inappropriate meaning in the short but not in the long ISI. This would be evident from a reduction of the N400 to the targets in the discordant relative to the unrelated condition.

To further determine whether possibly abnormal N400 effects in the Broca's aphasics could be related in a meaningful way to their specific comprehension deficit and not to their brain damage per se, three control procedures were implemented. First, to control for non-specific effects of aging on the N400, a group of normal agematched controls was tested. Second, the aphasic patients and their controls were tested in a control study with non-linguistic stimuli. For this control study we used the classical auditory oddball paradigm. Subjects were presented with a series of high and low tones. Their task was to count the infrequent (rare) low tones (oddballs), and to ignore the frequent high tones (standards). It has been shown that neurologically unimpaired subjects have a larger positive ERP-waveform to oddballs than to standard tones, the P300 effect [14]. Comparing the pattern of results of this control study to the pattern of results of the language study for the two subject groups, would help to determine the extent to which possible changes in the N400 effect in aphasic patients can be dissociated from the effects of brain damage on cognitive ERP-components in general. A dissociation between possible changes in the N400 effects and the P300 effects of the aphasic patients would support the conclusion that changes in the N400 effects are related to their linguistic deficit. In the third control measurement, the N400 to the targets in the lexical ambiguity conditions was compared to a standard N400 effect. This comparison was realized by adding two control conditions to the language experiment. In these control conditions, subjects were presented with pairs of sentences that contained either high- or low cloze probability words in mid-sentence position. The sentences in each pair were identical with the exception of the critical noun. For example (critical words are in bold): high cloze condition: "Jenny puts the candy in her mouth and walks to school"; low cloze condition: "Jenny puts the candy in her pocket and walks to school". The N400 was measured to the critical nouns in both conditions.

For the normal control subjects, a reduction of the amplitude of the N400 to the high cloze words relative to the low cloze words was expected, since the high cloze words are more easily integrated into the higher order representation of the preceding context [31]. In accordance with the results of Swaab et al. [70], for the Broca's aphasics, a delay in the integration of lexical information was expected to influence the N400 effect to the critical words in sentence medial position. Relative to the normal controls, the Broca's aphasics in the present study were predicted to show a delay and/or reduction of their N400 effect in these control conditions.

\section{Method}

\section{Subjects}

A group of 12 elderly controls ( 3 males, age between $51-72$ years, education between 6-24 years) and a group of 12 aphasic patients participated in this experiment. The testing procedures were approved by the ethical committee of the Nijmegen Academic Hospital. All the subjects gave informed consent. The elderly control subjects were paid for their participation and were approximately matched with the aphasic patients in age and level of education. All the control subjects were right handed according to an abridged version of the Oldfield Hand- 
Table 1. Summary of information on age, gender (sex), education (Edu), scores on the Token Test (TT) and performance on the AAT subtest comprehension (Overall Comp Score). The AAT comprehension scores are also given for sentence comprehension (Sent Comp) and auditory comprehension (Aud Comp) separately. Lesion site is given for the 11 aphasic patients for whom adequate $\mathrm{CT} / \mathrm{MRI}$ information was available. The mean age was 56 years $(r=29-74)$. Patients with moderate to severe comprehension deficits are indicated with $\mathrm{L}$ and patients with light to very mild comprehension deficits are indicated with $\mathrm{H}$

\begin{tabular}{|c|c|c|c|c|c|c|c|c|}
\hline Pat & Age & Sex & $\mathrm{Edu}^{\mathrm{a}}$ & $\mathrm{TT}^{\mathrm{b}}$ & $\begin{array}{c}\text { Overall } \\
\text { Comp } \\
\text { Score } \\
\text { AAT }^{\mathrm{c}}\end{array}$ & $\begin{array}{l}\text { Sent } \\
\text { Comp } \\
\text { Score } \\
\text { AAT }\end{array}$ & $\begin{array}{l}\text { Aud } \\
\text { Comp } \\
\text { Score } \\
\text { AAT }\end{array}$ & Lesion site $^{\mathrm{d}}$ \\
\hline $01 \mathrm{H}$ & 42 & $\mathrm{~m}$ & 12 & 17 & $94 / 120$ & $35 / 60$ & $45 / 60$ & Temporal-parietal \\
\hline $02 \mathrm{~L}$ & 62 & $\mathrm{~m}$ & 12 & 38 & $67 / 120$ & $27 / 60$ & $39 / 60$ & Dorsolateral frontal, ventrolateral frontal \\
\hline $03 \mathrm{H}$ & 67 & $\mathrm{~m}$ & 12 & 24 & $105 / 120$ & $53 / 60$ & $51 / 60$ & Dorsolateral frontal \\
\hline $04 \mathrm{~L}$ & 37 & $\mathrm{f}$ & 12 & 45 & $74 / 120$ & $31 / 60$ & $41 / 60$ & Temporal plane \\
\hline $05 \mathrm{H}$ & 48 & $\mathrm{f}$ & 12 & 10 & $97 / 120$ & $46 / 60$ & $49 / 60$ & Dorsolateral frontal, ventrolateral frontal \\
\hline $06 \mathrm{~L}$ & 71 & $\mathrm{~m}$ & 12 & 34 & $65 / 120$ & $28 / 60$ & $37 / 60$ & Posterior dorsolateral, frontal temporal-parietal \\
\hline $07 \mathrm{~L}$ & 69 & $\mathrm{~m}$ & 06 & 50 & $90 / 120$ & $44 / 60$ & $46 / 60$ & $\begin{array}{l}\text { Dorsolateral frontal, ventrolateral frontal, temporal } \\
\text { plane }\end{array}$ \\
\hline $08 \mathrm{H}$ & 73 & $\mathrm{f}$ & 18 & 07 & $108 / 120$ & $53 / 60$ & $52 / 60$ & Dorsolateral frontal, ventrolateral frontal \\
\hline $09 \mathrm{~L}$ & 44 & $\mathrm{~m}$ & 12 & 41 & $65 / 120$ & $32 / 60$ & $33 / 60$ & $\begin{array}{l}\text { Dorsolateral frontal, ventrolateral frontal, temporal- } \\
\text { parietal }\end{array}$ \\
\hline $10 \mathrm{H}$ & 55 & $\mathrm{~m}$ & 18 & 13 & $98 / 120$ & $55 / 60$ & 49/60 & $\begin{array}{l}\text { Posterior dorsolateral prefrontal, ventrolateral pre- } \\
\text { frontal }\end{array}$ \\
\hline $11 \mathrm{~L}$ & 74 & $\mathrm{f}$ & 28 & 20 & $87 / 120$ & $42 / 60$ & $41 / 60$ & - \\
\hline $12 \mathrm{H}$ & 29 & $\mathrm{~m}$ & 12 & 24 & $93 / 120$ & $45 / 60$ & $47 / 60$ & Dorsolateral frontal \\
\hline
\end{tabular}

${ }^{\mathrm{a}}$ Total number of years of education.

${ }^{\mathrm{b}}$ Severity of disorder as indicated by the Token Test (TT): no/very mild disorder (0-6); light (7-23); middle (24-40); severe (>40).

${ }^{\mathrm{c}}$ Severity of comprehension disorder as indicated by the AAT subtest Comprehension (includes word and sentence comprehension in both auditory and visual modality): severe (1-66); middle (67-89); light (90-106); no/very mild disorder (107-120). Ranges of severity are based on the norms of the Dutch version of the AAT.

${ }^{\mathrm{d}}$ Anatomical description of the lesion site.

edness Inventory [57]. Two of them reported familial left handedness. The aphasic patients were all premorbidly right handed. According to the responses on a second questionnaire, none of the elderly control subjects had any known neurological impairments or used any neuroleptics. None of the control subjects reported hearing loss or memory problems.

All patients were tested with the standardized Dutch version of the Aachen Aphasia Test (AAT) [26]. Time of administration was at least six months post onset. Both the presence and the type of aphasia were diagnosed on the basis of their AATresults and on the basis of a transcribed sample of their spontaneous speech. All patients were diagnosed as Broca's aphasics. According to their scores on the comprehension subtest of the AAT, aphasic patients varied in the severity of their comprehension deficit between very mild and severe. Table 1 summarizes the relevant information for the aphasic patients. Although each of the patients was clearly diagnosed with Broca's aphasia on the basis of the results of the AAT, in many of the patients the site of the lesion was not confined to Broca's area. This confirms the results from earlier studies that found

* The second list was made by Dr Riet Coolen and the third list by Dr Jos van Berkum at the Max Planck Institute for Psycholinguistics in Nijmegen.

$\dagger$ Even though subjects did not have to respond to the words that followed the sentences in the three context conditions (see Procedure), these words will be called targets in this study. This is done in order to be consistent with the nomenclature that is used in the literature. patients with Broca's aphasia that had lesions involving more than Broca's area alone $[2,16]$.

Figure 1 gives the averaged CT-lesion data for these patients. The averaged lesion is centered in the posterior frontal lobe, somewhat superior to Broca's area. This area has overlap of lesion in about $73 \%$ of the cases.

\section{Stimuli}

Noun-noun ambiguities with a dominant and a subordinate meaning were selected from three lists of Dutch words with two or more unrelated meanings [31]*. For 302 ambiguous Dutch words, the relative frequencies of the distinct meanings as well as the first associates had been established by testing 212 subjects of the University of Nijmegen. For each ambiguous noun a set of three context sentences with a relatively simple sentence structure was constructed. These context sentences were divided over three experimental conditions. In each condition, the sentence was followed by the same target word. $\uparrow$ Table 2 presents examples of the stimulus materials in the three conditions.

In the concordant condition, the sentence context biased the subordinate meaning of the ambiguous noun, and this meaning was related to the target word. In the discordant condition, the sentence biased the dominant meaning of the sentence final ambiguous noun. This meaning was unrelated to the target word. In the unrelated condition, the sentence had an unambiguous noun as its sentence-final word. The meaning of the unambiguous noun was unrelated to the target word. Each set 


\section{Averaged Lesions Across Patients}

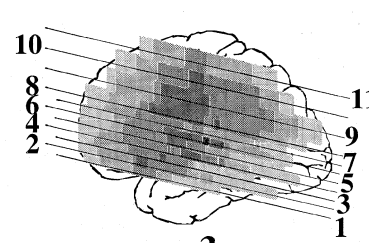

3

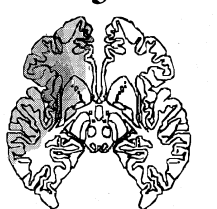

6

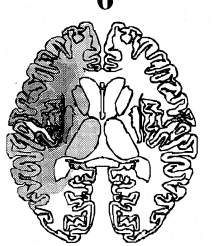

9
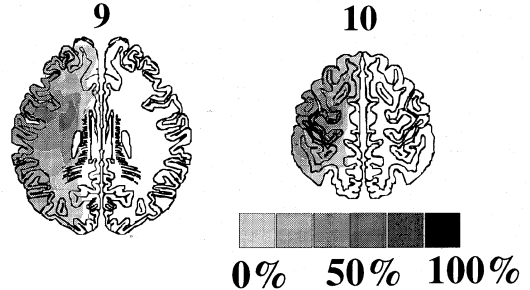

2

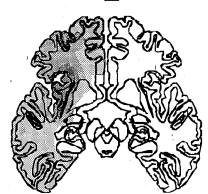

5

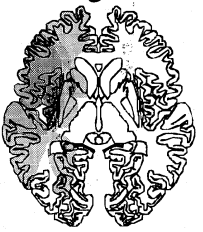

8

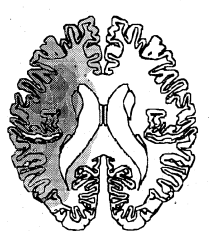

11

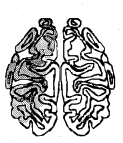

Fig. 1. Lesion extent in the Broca's aphasics. Lesions determined by available CT/MRI-scans from individual patients were transcribed onto $0^{\circ}$ to canthomeatal line templates. These lesion data were then read into a reconstruction program [43]. The digitized data were averaged to generate the group lesion densities. The 11 lines through the lateral reconstruction indicate 11 axial sections. The scale indicates the percentage of patients having involvement of that brain region. Lesions were averaged over 11 patients.

of three context sentences had the same constituent structure. The content words in the sentences were never associatively related to the sentence-final word or the target presented after the sentence [66]. Furthermore, no salient features of the meaning of the ambiguity were primed by the sentence context $[75$, 76].

Pretests. The sentences were submitted to a series of pretests.
First, they were tested in a cloze test. In this cloze test, 64 paid subjects from the University of Nijmegen were presented with the sentences in random order, with the sentence-final word omitted. The subjects were instructed to fill in a last word that best fit the context of the preceding sentence. The cloze test was performed to test the predictability of the sentence-final ambiguous nouns and the sentence-final unambiguous nouns as a function of the sentence context. This predictability should not be too high in order to avoid pre-selection of the contextually appropriate meaning of the ambiguous noun by guessing the sentence-final word. Selection of the context sentences was therefore done according to two criteria. In the selected sentences, the maximum cloze probability for the sentence-final noun did not exceed $45 \%$ and the mean cloze probability was matched between conditions. The cloze procedure led to the rejection of two problematic triplets.

Following this cloze procedure, an association test was performed to establish whether the sentence context was successful in biasing the intended reading of the sentence-final ambiguous noun. For the sentences ending in an unambiguous noun, this test should confirm that the context was a proper control, in that the target word was never given as a response. In this test, the complete context sentences were presented to the subjects. Subjects were required to read the sentence and to write down the first word that came to mind upon reading the sentencefinal word. The two sentences ending in the same ambiguous word were assigned to two different versions of the association test. The unrelated sentences were divided over the two versions. In this way none of the subjects saw a sentence-final word more than once. Each version of the association test was given to 20 paid subjects from the University of Nijmegen that had not participated in the cloze test.

In the association test the sentences that ended with an ambiguous noun were tested on the following criteria: At least $60 \%$ of the answers in the association test should be in the direction of the biasing context and at most $25 \%$ of the answers should be related to the unintended reading of the ambiguous noun. For the sentences that ended in an unambiguous noun at least $70 \%$ of the answers should be related to the meaning of this sentence-final noun. This test led to the rejection of another twelve problematic items. After these pretests, 50 sentence triplets remained that were used in the present study.

Selected materials. Targets words were selected from the three lists that were described at the beginning of the stimuli section. The highest $(94 \%)$ or second highest associate of the subordinate reading was chosen as a target. The average frequency of occurrence for the subordinate meaning of the 50 ambiguous words was $19 \%(r=2-40)$. The minimum difference between the frequency of occurrence of the dominant and the subordinate readings of the ambiguous words was $20 \%$. The sentences had a mean length of 8.6 words ( $r=6-13$ words).

The results from the cloze tests revealed that the mean cloze

Table 2. Examples of sentences in the three context conditions. The sentence-final words and the targets are in capitals (with literal English translations in brackets)

\begin{tabular}{lll}
\hline Context condition & Sentence & Target word \\
\hline Concordant & $\begin{array}{l}\text { De chirurg verwijdert kundig de pijnlijke AMANDELEN } \\
\text { (The surgeon removes skilfully the painful TONSILS }\end{array}$ & $\begin{array}{l}\text { KEEL } \\
\text { THROAT) }\end{array}$ \\
Discordant & $\begin{array}{l}\text { De jongen pikt snel de grootste AMANDELEN } \\
\text { (The boy takes quickly the biggest ALMONDS }\end{array}$ & KEEL \\
THrelated & $\begin{array}{l}\text { Te krant publiceert vandaag deze knappe SPOTPRENTEN } \\
\text { (The newspaper publishes today these good CARTOONS }\end{array}$ & KEEL \\
& & THROAT) \\
\hline
\end{tabular}


probability for the sentence-final nouns was less than $7 \%$ $(r=0-34)$. None of the target words were mentioned more than once in these tests.

The strength of the contextual bias for the selected sentences was computed from the results of the association tests. On average $90 \%$ of the responses to the concordant context sentences was related to the intended, subordinate meaning and $3 \%$ to the unintended, dominant meaning. For the discordant context sentences, a mean of $85 \%$ was related to the intended, dominant meaning and $7 \%$ to the unintended subordinate meaning. These results indicate that the context sentences were successful in biasing the intended meaning of the ambiguous sentence-final nouns. Moreover, the bias was comparable in strength for the different conditions. Finally, the target word was never given as a response in the unrelated control sentences.

Control sentences. In addition to the 50 sentence triplets, 120 control sentences were constructed. Sixty were sentences containing a high-cloze probability word and 60 were sentences containing a low-cloze probability word in mid-sentence position. These sentences were included to elicit a standard N400 effect, which could be compared to the ERP effects to the targets in the experimental sentences that were described in the previous section. The control sentences were constructed in pairs. The sentences in each pair were identical with the exception of the critical noun in mid-sentence position. This noun was highly predictable in one condition (high-cloze condition), and less expected in the other condition (low-cloze condition). Establishment of the cloze probability of these items is described elsewhere [34]. The mean cloze probability for the high cloze nouns was $58 \%$ and for the low cloze nouns it was $7 \%$. In both the high and the low cloze conditions the sentences ended in an unambiguous word and were followed by an unrelated target. The same target was used in each high-low cloze pair. None of these targets occurred as a sentence-final word or a target in the experimental triplets described earlier. An example of the sentences in the high- and low cloze conditions is given in the following (the critical noun is in bold, literal English translation is in brackets, target word was MUSEUM):

High Cloze:

"De kinderen drinken elke dag melk bij het ontbijt MUSEUM",

(The children drink each day milk at breakfast MUSEUM).

Low Cloze:

"De kinderen drinken elke dag limonade bij het ontbijt MUSEUM".

(The children drink each day lemonade at breakfast MUSEUM).

In the combined set of experimental triplets and control sentences, less than half of the sentence-final words was related to the target, which made the development of strategies to predict a relation between sentence-final word and target unlikely.*

An additional 12 startup items were constructed, half of them followed by a related target and the other half followed by an unrelated target. Finally, 19 practice sentences were constructed, half of them with a related target and half of them with an unrelated target.

All materials were spoken at normal rate and with normal intonation by an experienced female speaker in a sound-attenuating booth. The control sentences, the experimental sentences and the targets were recorded on a digital audio tape and stored on a hard disk. A speech waveform editing system was used to

* Furthermore, given the fact that subjects had no task that urged them to generate a fast response, it is unlikely that they developed a response-related strategy. add targets to their respective sentences. Identical targets were represented by the same physical token. The same materials were used in the two ISI versions of the experiment. In version one, the ISI was $100 \mathrm{~ms}$, in version two it was $1250 \mathrm{~ms}$. Timelocking for signal averaging was established by placing a trigger pulse before each sentence at a fixed interval to the sentence final ambiguity. The inter-trial-interval was $6415 \mathrm{~ms}$ in both versions of the experiment. Digital audio tapes were constructed that contained the sentence materials. In addition, a questionnaire was prepared with 15 questions about the sentence content of 15 of the control sentences, 5 questions for each block. Finally, a digital audio tape was constructed with tones for the non-linguistic oddball task as described elsewhere [36, 70].

\section{Procedure}

All the subjects were tested in two sessions of about $2.5 \mathrm{~h}$, one session for each ISI version. They were always first tested in the short ISI version. In each ISI version, the control sentences were randomly intermixed with the experimental sentences. These language materials were divided into three experimental blocks. Targets and ambiguous words were never repeated within a block. Within one ISI session, each target word was repeated three times and each ambiguous word twice over the three blocks. The sentences were not repeated (see Table 2 for an example).

The presentation order of the blocks was counterbalanced, resulting in three presentation versions. Subjects were assigned to one of three presentation versions so that four normal controls and four Broca's aphasics were tested in each. In the long ISI session, the same language materials were presented as in the short ISI session. To minimize effects of repetition, the ISI sessions were separated by at least three weeks. In the second ISI session, after the language experiment, all subjects were tested in the tone oddball experiment.

The subjects were tested individually in a dimly illuminated sound-attenuating booth, seated in a comfortable reclining chair. One patient was tested in his wheelchair. Subjects were instructed to move as little as possible and to keep their eyes fixated on a point at eye level. With respect to blinks no instruction was given (blinks were corrected with an off-line procedure described by Gratton et al. [27]). The subjects were told that they would hear sentences followed by a word. They were asked to listen attentively to the materials and they were told that the experimenter would sometimes stop the tape to ask them a question about a sentence they had just heard. No additional tasks were imposed.

All the stimuli were presented via a DAT-recorder (SONY 300ES). The subjects listened to the stimuli via a closed-ear Sennheiser HMD-224 headphone. The trigger pulse on the right channel of the test tapes was inaudible to the subjects.

The total duration of the stimulus presentation was $58 \mathrm{~min}$ in the ISI $=100$ version and 64 minutes in the ISI $=1250$ version Each session started with the practice list to familiarize the subjects with the stimulus situation and to train them to fixate their eyes. If necessary, the practice list was repeated for the patients. About every $3 \mathrm{~min}$ a question was asked about the contents of a control sentence and in addition, the subjects were asked to repeat the word that followed the sentence that was questioned. This was done to establish that the subjects were listening to the sentences. The answer was written down by the experimenter. If necessary, a short break was given after asking a question. All the subjects were given a break of about $10 \mathrm{~min}$ after each experimental block and before the tone oddball. After the three experimental blocks the experimenter asked the subjects what aspects of the experiment were noticeable to them and their answers were written down. The practice session of the tone oddball was used to establish whether patients were 
able to silently count the low tones. Four patients were unable to count. For these subjects it was established during the practice session that they could discriminate high versus low tones (by raising their hand) and they were instructed to listen attentively without an additional task.

\section{EEG-recording}

The EEG was recorded from seven tin electrodes in an electrode cap, each referred to the left mastoid. Three electrodes were placed according to the International 10-20 system [40] over midline sites at $\mathrm{Fz}, \mathrm{Cz}$ and $\mathrm{Pz}$ locations. Four electrodes were placed laterally over symmetrical anterior and posterior positions. The symmetrical anterior electrodes (AL, AR) were located one half of the distance between F7 and T3 and F8 and T4 sites. The symmetrical posterior electrodes (PL, PR) were located $30 \%$ of the interaural distance lateral to a point $13 \%$ of the nasion-inion distance posterior to Cz. Vertical and horizontal eye movements were monitored via sub- and supraorbital electrodes and left and right external canthus montages, respectively. The ground electrode was placed on the forehead, $10 \%$ from the nasion-inion distance above the nasion.

The EEG and EOG recordings were amplified by Nihon Kohden AB-601G bioelectric amplifiers. A low-pass filter cutoff of $30 \mathrm{~Hz}$ was used with a time constant of $8 \mathrm{~s}$. The impedances were kept below $5 \mathrm{~K}-\mathrm{Ohm}$. The signal was digitized online with a sampling frequency of $200 \mathrm{~Hz}$. The trigger pulse started sampling $150 \mathrm{~ms}$ before the presentation of a sentence. The total sampling epoch per trial was $8400 \mathrm{~ms}$ for the stimuli in the ISI $=1250 \mathrm{~ms}$ version and $7400 \mathrm{~ms}$ in the ISI $=100 \mathrm{~ms}$ version. Data were stored on a hard disk along with condition codes for off-line averaging and data analysis.

\section{Results}

First the N400 results will be presented for the linguistic control conditions, and for the lexical ambiguity conditions, for the ISI $=100 \mathrm{~ms}$ and the ISI $=1250 \mathrm{~ms}$ versions separately and for both ISI versions compared in one analysis. For the ambiguity conditions, inspection of the waveforms showed differences in addition to the N400 in a later part of the waveform. Analyses are also reported for these late positivities, for the ISI $=100$ and the ISI $=1250 \mathrm{~ms}$ versions separately. Then the P300 effects will be presented. In each section, the results will be discussed for the normal controls and the Broca's aphasics. Because the results from previous ERP studies indicate a clear difference in the size of the N400 effects for the aphasic patients as a function of the severity of their comprehension deficit, additional analyses will be presented with the patients divided into a group of high

* Our a priori prediction was that we would find the N400 effects to be maximal over centro-posterior electrode sites. However, additional analyses including all electrode sites showed the same pattern of results for the ambiguity manipulations compared to the analyses over centro-parietal sites only.

$\dagger$ Since the high and the low cloze words in the mid-sentence position were not affected by the ISI manipulation, it was sufficient to analyse the effect of Cloze Probability over the first presentation only. comprehenders and a group of low comprehenders [36, 70]. This was done on the basis of a median split of their scores on the comprehension subtest of the AAT. The six high comprehenders had a mean comprehension score of $99(\mathrm{SD}=6.0)$. The low comprehenders scored 75 $(\mathrm{SD}=10.7)$ (see Table 1 for individual subject information). Additional analyses will also be reported for the P300 data for the high and the low comprehenders. Finally, individual subject data will be presented.

\section{Analysis of N400 effects}

Prior to off-line averaging, all single trial waveforms were screened for electrode drifting, amplifier blocking, muscle artifacts, eye movements and blinks. This was done over a $2000 \mathrm{~ms}$ epoch, starting $150 \mathrm{~ms}$ before the targets in the experimental sentences (in the different context conditions) and the critical words in the control sentences (the high and low cloze words). Trials containing such artifacts were rejected. However, for subjects with a substantial number of blinks, those single trials that were without amplifier blocking were corrected for eye blinks using a procedure described by Gratton et al. [27] and included in the relevant ERP averages.

Statistical analyses were carried out on the mean amplitude of the N400, using repeated-measures analysis of variance (ANOVA). The N400 effects showed the expected posterior distribution [49], both in the linguistic control conditions and in the lexical ambiguity conditions and the ANOVAs were therefore done on the values of the centroparietal electrode sites. ${ }^{*}$ When evaluating effects with more than one degree of freedom in the numerator, the Greenhouse-Geisser correction was applied [28, 81]. The adjusted degrees of freedom and $P$ values will be presented.

Given that lesion consequences on volume conduction are not easy to quantify, one has to be very careful in assigning a cognitive-functional interpretation to subtle differences in the scalp distributions of the ERP effects between the different subject groups. Although we will describe the distributional aspects of the effects, as a result of this difficulty of quantifying lesion consequences on scalp topography, we will not attach any substantial functional significance to distributional differences between subject groups.

\section{N400 to high and low cloze words in mid-sentence position}

Average waveforms were computed over the trials that remained after artifact rejection for each subject over the high and the low cloze words. $\dagger$ The overall rejection rate was $22 \%$ for the normal controls, and $21 \%$ for the aphasic patients $(18 \%$ for the low comprehenders and $24 \%$ for the high comprehenders). An ANOVA was done on the mean amplitude of the N400 to the high and low cloze words in the 350-600 ms latency window, nor- 
malized to a $150 \mathrm{~ms}$ baseline, with the within-subject variables Cloze Probability (High Cloze vs Low Cloze) and Electrode Site (Cz, Pz, PL, PR). This latency window was chosen because it allows a direct comparison of the N400 results in the high/low cloze control conditions with the N400 effects to the targets following the sentences in the three ambiguity conditions. The averaged waveforms for the critical words in the high and low cloze conditions are shown for the controls in Fig. 2, and for the Broca's aphasics in Fig. 3.

As can be seen in Figs 2 and 3, no clear N1 and P2 components are visible in the waveforms for either the normal controls or the Broca's aphasics. This absence is due to the fact that the words in both cloze conditions were embedded in the continuous speech stream [39, 70]. Both normal controls and Broca's aphasics show a clear N400 effect: The waveforms to the low cloze words are more negative than the waveforms to the high cloze words for both subject groups. In both groups, the effect has a centroparietal distribution. The normal controls show a somewhat larger effect over the right than over the left hemisphere. Finally, the effect appears to be larger and to have an earlier onset in the normal controls, than in the Broca's aphasics.

For the normal controls the size of the N400 effect was $-1.96 \mu \mathrm{V}$, which was statistically significant

NORMAL CONTROLS $(\mathrm{N}=12)$, Critical Word in Mid-Sentence Position

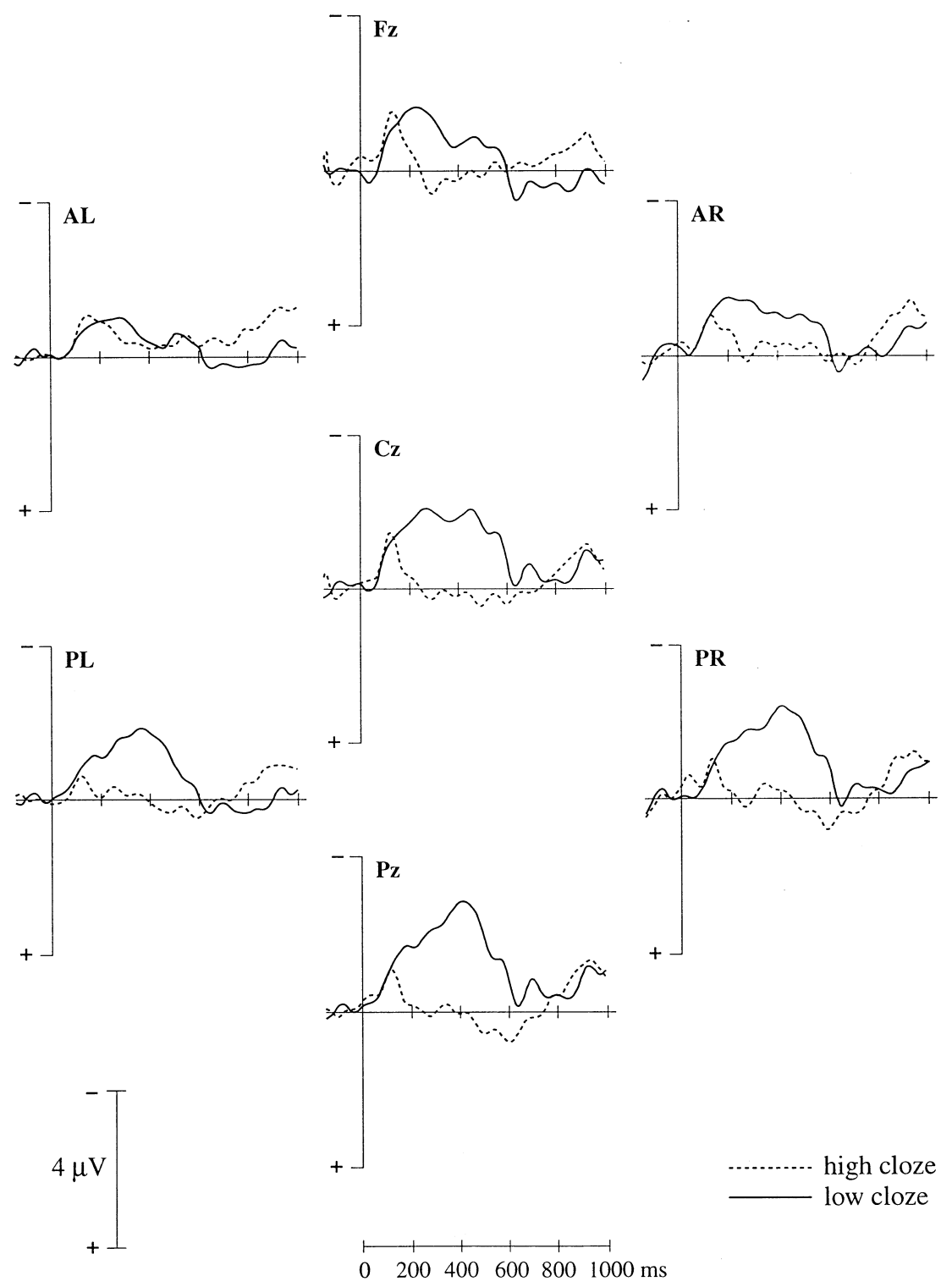

Fig. 2. Grand average ERPs from the normal controls $(n=12)$ to the low cloze (solid line) and high cloze (dotted line) critical words in mid-sentence position. 
BROCA'S APHASICS ( $\mathrm{N}=12)$, Critical Word in Mid-Sentence Position

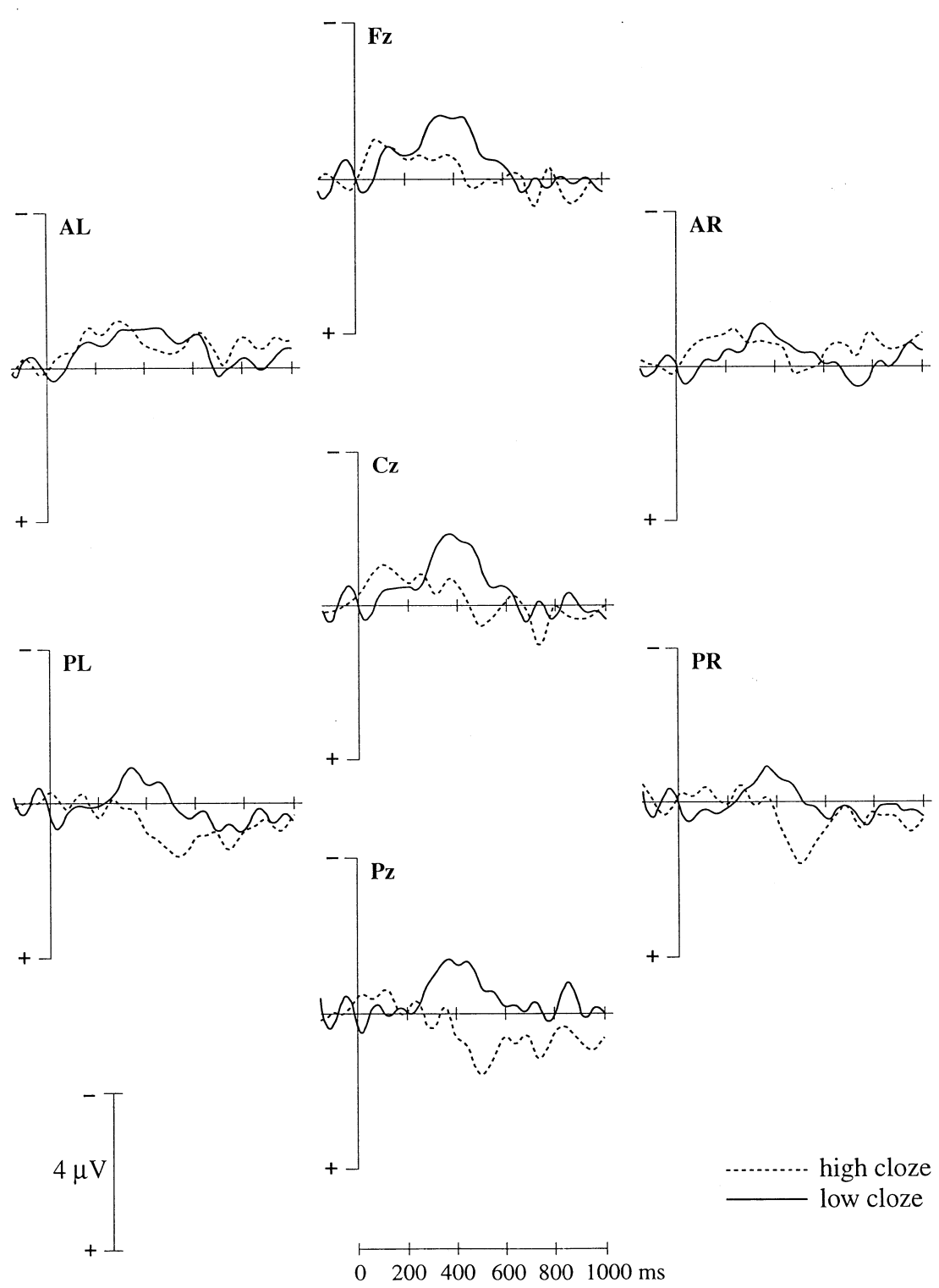

Fig. 3. Grand average ERPs from the Broca's aphasics $(n=12)$ to the low cloze (solid line) and high cloze (dotted line) critical words in mid-sentence position.

$(F(1,11)=11.64, \mathrm{MSe}=7.92, P<0.006)$. The Broca's aphasics also had a statistically significant N400 effect of $-1.30 \mu \mathrm{V}(F(1,11)=5.88, \mathrm{MSe}=6.86, P<0.04)$.

The effect of Cloze Probability was clearly influenced by the severity of the comprehension deficit: In the ANOVA dividing the Broca's aphasics into a group of high comprehenders and a group of low comprehenders, with Group of Subjects as the additional factor, there was a significant Group of Subjects by Cloze Probability interaction $(F(1,10)=6.72, \mathrm{MSe}=4.51, P<0.03)$. Subsequent ANOVAs for the high and the low comprehenders separately revealed a significant effect of Cloze Probability for the high comprehenders $(-2.42$ $\mu \mathrm{V} ; F(1,5)=24.08, \mathrm{MSe}=9.11, P<0.005)$, but for the low comprehenders the effect was not significant $(-0.17$ $\mu \mathrm{V} ; F<1)$.

\section{N400 to target words}

Average waveforms were computed for each subject over the trials that remained after artifact rejection for the targets in the three context conditions. The overall rejection rate was $16 \%$ for the normal controls and $21 \%$ for the Broca's aphasics: $16 \%$ for the high comprehenders and $26 \%$ for the low comprehenders. First, an overall repeated measures ANOVA was done on the mean amplitude of the N400 in the 350-600 ms epoch after target 
onset, relative to a $100 \mathrm{~ms}$ pre-stimulus baseline, with as the within-subject variables Congruency (Concordant (C), Discordant (D), Unrelated (U)) and Electrode Site $(\mathrm{Cz}, \mathrm{Pz}, \mathrm{PL}, \mathrm{PR})$. The analysis epoch was determined on the basis of visual inspection of the waveforms. In addition to the overall repeated measures ANOVAs, planned comparisons were carried out, comparing the unrelated condition relative to the concordant condition (U-C), the unrelated condition relative to the discordant condition (U-D) and the discordant condition relative to the concordant condition (D-C). The analyses will be reported for the short and the long ISI version separately. Finally, an ANOVA will be reported in which the context effects in the short and the long ISI version were compared, with ISI as the additional factor.

$$
I S I=100
$$

Normal controls. The averaged waveforms for the group of 12 normal control subjects for the targets in each context condition are presented in Fig. 4.

As is evident from Fig. 4, the waveforms show small $\mathrm{N} 1$ and $\mathrm{P} 2$ components, that are reduced in amplitude because the ISI between sentence-final word and target was only $100 \mathrm{~ms}$ and these components need longer ISIs to regain their full amplitude [42]. Overall, the P2 component is larger in amplitude in the concordant and discordant conditions than in the unrelated condition. However, this difference might be due to an overlapping differential N400 [36]. N1 and P2 components are followed by the N400. The N400 has a clear centroparietal distribution. The amplitude of the N400 is reduced in the concordant condition relative to the unrelated and discordant conditions. There also appears to be a slight reduction of the N400 to the targets in the discordant condition relative to the unrelated condition.

An overall ANOVA was done that had Order of Presentation (block 1,2,3; block 2,3,1; block 3,1,2) as the additional factor, with subjects nested under Order of Presentation. There was no Order of Presentation by Congruency interaction $(F(2,9)=1.42, \quad \mathrm{MSe}=5.68$, $P=0.28)$, indicating that Order of Presentation had no influence on the results. The difference between conditions was substantiated as a significant main effect of Congruency $(F(1,9)=12.79, \mathrm{MSe}=5.68, P<0.01)$.

Planned comparisons of the N400 effect in the different context conditions revealed a significant reduction of the N400 amplitude to the targets in the concordant condition relative to the unrelated condition ( $\mathrm{U}-\mathrm{C}=-2.39$ $\mu \mathrm{V} ; F(1,9)=19.24, \mathrm{MSe}=7.09, P<0.002)$ and also relative to the discordant condition $(\mathrm{D}-\mathrm{C}=-1.72 \mu \mathrm{V}$; $F(1,9)=12.24, \mathrm{MSe}=5.78, P<0.007)$. The difference in the N400 amplitudes to the targets in the unrelated and discordant condition was not significant (U-D $=-0.68$ $\mu \mathrm{V} ; F(1,9)=2.56, \mathrm{MSe}=4.17, P=0.14)$.

Broca's aphasics. Figure 5 presents the average wave- forms to the targets in the three context conditions for the group of 12 Broca's aphasics.

The N1 and P2 components for the Broca's aphasics are reduced and/or absent in the waveforms. However, just as for the normal controls, the waveforms for the aphasic patients show a clear N400 that has a centroparietal distribution and is reduced in amplitude to the targets in the concordant condition relative to the unrelated condition. In contrast to the normal controls who showed no significant reduction of the N400 amplitude to the targets in the discordant condition relative to the unrelated condition, the Broca's aphasics show a substantial difference between these two conditions.

The overall ANOVA on the mean amplitude of the N400 to the targets in the different context conditions revealed that Order of Presentation did not interact with Congruency $(F<1)$ and that the main effect of Congruency was significant $(F(1,9)=14.04, \quad \mathrm{MSe}=5.78$, $P<0.01)$. Just as for the normal controls, the N400amplitude to the targets in the concordant condition was significantly reduced relative to the unrelated condition $(\mathrm{U}-\mathrm{C}=-2.60 \quad \mu \mathrm{V} ; \quad F(1,9)=19.56, \quad \mathrm{MSe}=8.30$, $P<0.002)$ and the discordant condition (D-C $=-1.28$ $\mu \mathrm{V} ; F(1,9)=8.00$, MSe $=4.91, P<0.01)$. But, importantly, in contrast to the normal controls the difference between the discordant and the unrelated condition was significant as well $(\mathrm{U}-\mathrm{D}=-1.32 \mu \mathrm{V} ; F(1,9)=10.14$, $\mathrm{MSe}=4.13, P<0.02)$.

High vs low comprehenders. The ANOVA with Group of Subjects (high comprehenders, low comprehenders) as the additional factor revealed that there was no significant Group of Subjects by Congruency interaction $(F<1)$. This indicates that the severity of the comprehension deficit had no clear influence on the pattern of results. Therefore, no additional analyses were done for the group of high and the group of low comprehenders separately.

$I S I=1250$

The artifact rejection and the analyses of variance were done according the procedures that were described for the short ISI version. The overall rejection rate was $22 \%$ for the normal controls and $23 \%$ for the Broca's aphasics; $20 \%$ for the high comprehenders, and $25 \%$ for the low comprehenders.

Normal controls. The averaged waveforms for the twelve normal controls for the targets in the three context conditions are shown in Fig. 6. As can be seen in this Figure, with an ISI of $1250 \mathrm{~ms}$ the waveforms now show clear N1 and P2 components. These components are followed by the $\mathrm{N} 400$, that is larger over centroparietal leads. The amplitude of the N400 to the targets in the concordant condition is reduced relative to the unrelated condition. The N400 to the targets in the discordant and the unrelated conditions are initially on top of each other, but after about $550 \mathrm{~ms}$ they start to diverge. 
ELDERLY NORMAL CONTROLS (N=12), ISI = $100 \mathrm{~ms}$

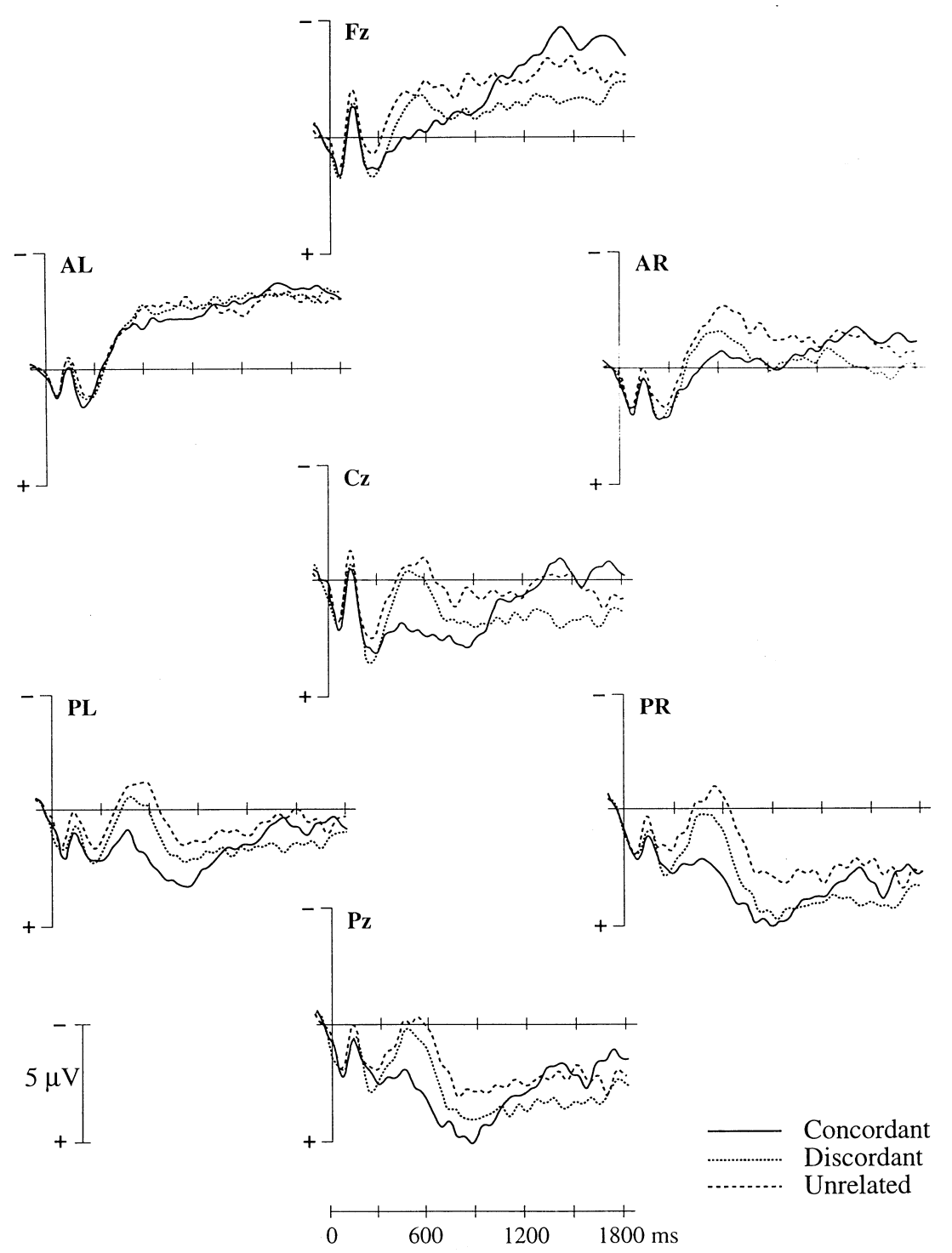

Fig. 4. Grand average ERPs from the normal controls $(n=12)$ in the short $(100 \mathrm{~ms})$ ISI version to the targets in the concordant (solid line), discordant (dotted line) and unrelated (dashed line) lexical ambiguity conditions.

An overall ANOVA on the mean amplitude of the N400 showed that Order of Presentation did not interact with Congruency $(F<1)$. A significant main effect of Congruency was obtained $(F(1,9)=17.23, \mathrm{MSe}=2.90$, $P<0.01)$. Planned comparisons showed a significant reduction of the amplitude of the $\mathrm{N} 400$ in the concordant relative to both the unrelated condition $(\mathrm{U}-\mathrm{C}=-1.95$ $\mu \mathrm{V} ; F(1,9)=33.62, \mathrm{MSe}=2.71, P<0.0002)$, and the discordant condition (D-C $=-1.49 \mu \mathrm{V} ; F(1,9)=15.17$, $\mathrm{MSe}=3.53, P<0.004)$. There was no significant difference in the N400 amplitude to targets in the discordant and the unrelated condition $(\mathrm{U}-\mathrm{D}=-0.45 \mu \mathrm{V} ; F(1,9)=$ 2.03, $\mathrm{MSe}=2.44, P<0.19$ ).

Broca's aphasics. The averaged waveforms for the twelve Broca's aphasics for the targets in the three context conditions are shown in Fig. 7.

Compared to the normal controls, the N1 and P2 components in the target waveforms for the Broca's aphasics are reduced (Figs 6 and 7). But, just as the normal controls, the patients show a clear N400 component with a centroparietal maximum. As in the short ISI version of the experiment and comparable to the normal controls, the amplitude of the N400 to the targets in the concordant condition was reduced relative to the unrelated and discordant conditions. Importantly, and in contrast to the short ISI version, the N400 to the unrelated and the discordant conditions mostly overlapped.

The overall ANOVA showed that Order of Pres- 
BROCA'S APHASICS (N=12), ISI = $100 \mathrm{~ms}$
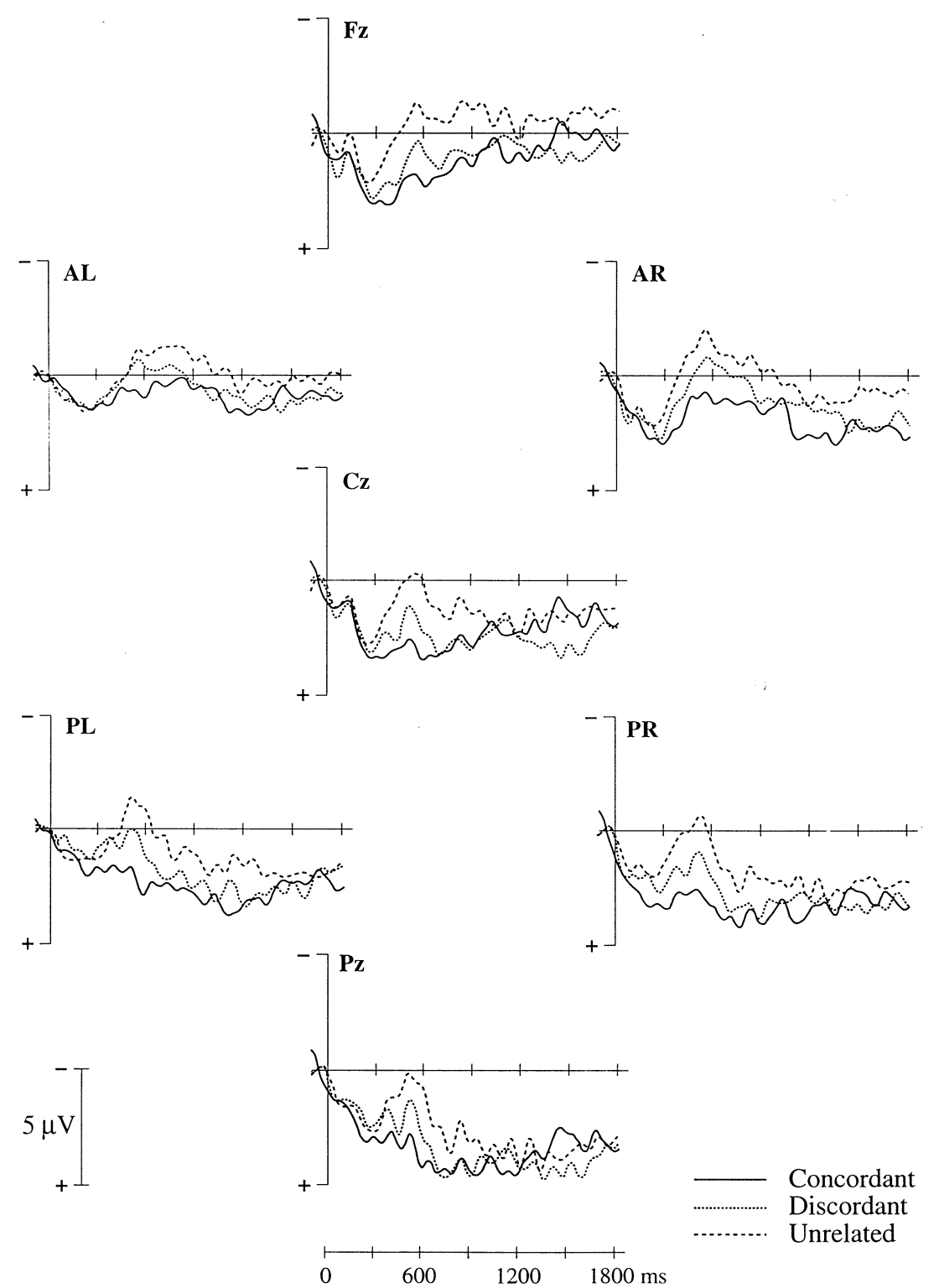

Fig. 5. Grand average ERPs from the Broca's aphasics $(n=12)$ in the short (100 ms) ISI version to the targets in the concordant (solid line), discordant (dotted line) and unrelated (dashed line) lexical ambiguity conditions.

entation had no significant influence on the pattern of results (Order of Presentation $\times$ Congruency: $F<1$ ). As for the normal controls a significant effect of Congruency was obtained $(F(1,9)=5.84, \mathrm{MSe}=7.16, P<0.02)$. Planned comparisons revealed a marginally significant difference between the concordant and the unrelated condition $(\mathrm{U}-\mathrm{C}=-1.50 \mu \mathrm{V} ; F(1,9)=4.84, \mathrm{MSe}=11.16$, $p=0.055)$, and a significant difference between the concordant and the discordant condition (D-C $=-1.71 \mu \mathrm{V}$; $F(1,9)=17.78, \mathrm{MSe}=3.96, P<0.003)$. But, in contrast to the short ISI, there was no longer a difference in the amplitude of the N400 to the targets in the discordant and the unrelated condition ( $\mathrm{U}-\mathrm{D}=+0.21 \mu \mathrm{V} ; F<1)$.

High vs low comprehenders. The ANOVA with Group of Subjects (high comprehenders, low comprehenders) as the additional factor revealed that just as in the short ISI version, there was no significant Group of Subjects by Congruency interaction $(F(1,10)=2.85, \quad \mathrm{MSe}=5.20$, $P=0.14$ ). This indicates that the pattern of results was comparable for the high and the low comprehenders, and therefore, no additional analyses were done for the group of low comprehenders and the group of high comprehenders separately.

Comparison of $I S I=100$ with $I S I=1250$

Normal controls. The ANOVA comparing the results for the different context conditions in the two ISI versions showed that there was no ISI by Congruency interaction 
ELDERLY NORMAL CONTROLS (N=12), ISI = $1250 \mathrm{~ms}$

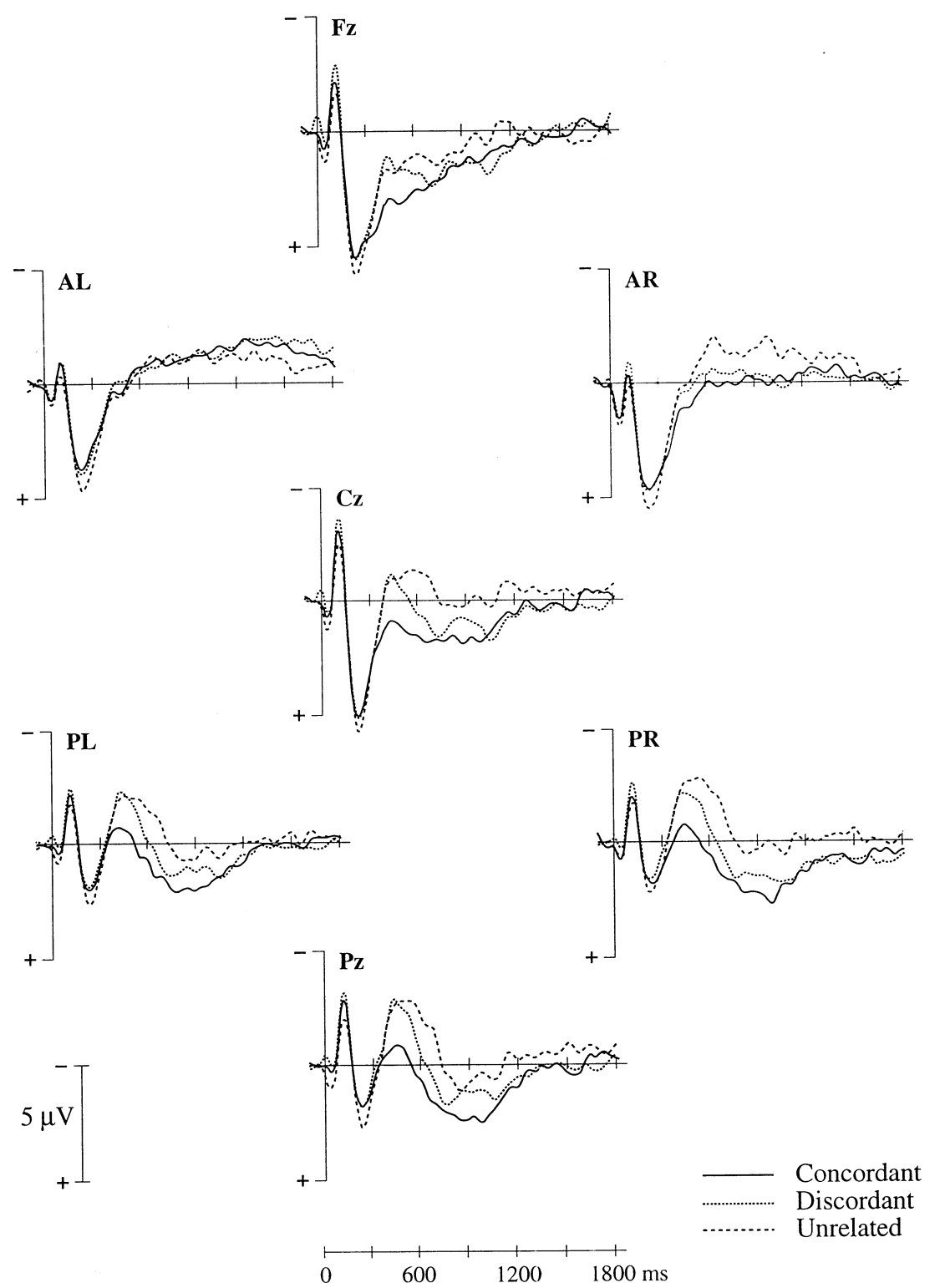

Fig. 6. Grand average ERPs from the normal controls $(n=12)$ in the long $(1250 \mathrm{~ms})$ ISI version to the targets in the concordant (solid line), discordant (dotted line) and unrelated (dashed line) lexical ambiguity conditions.

in any of the comparisons for the normal controls (U-C: $F<1$; U-D: $F<1$; D-C: $F<1$ ).

Broca's aphasics. For the Broca's aphasics, there was a significant ISI by Congruency interaction for the N400 effect in the comparison of the unrelated and the discordant condition $\quad(F(1,22)=6.39, \quad \mathrm{MSe}=4.41$, $P<0.02$ ), while this interaction was not significant for the other comparisons (U-C: $F(1,22)=1.64$, $\mathrm{MSe}=8.83, P=0.21 ; \mathrm{D}-\mathrm{C}: F<1)$.

\section{Analyses of late positive effects}

Statistical analyses of the late positive effects were performed on the mean amplitude in the 600-1000 ms win- dow and done in exactly the same way as the N400 analyses for the target words. This window was chosen on the basis of visual inspection of the waveforms. Only planned comparisons will be reported.

Normal controls, $I S I=100$. As can be seen in Fig. 4, over the centro-posterior sites the N400 is followed by a positive deflection in all conditions. The pattern of results for this positive deflection appears to deviate somewhat from the N400: Whereas the difference between unrelated and discordant condition seems larger in the $600-1000$ ms window, the difference between the concordant and the discordant condition seems smaller.

The planned comparisons for the normal controls revealed a significant difference between the unrelated and the concordant condition $(\mathrm{U}-\mathrm{C}=-2.14 \mu \mathrm{V}$, 
BROCA'S APHASICS $(\mathrm{N}=12), \mathrm{ISI}=1250 \mathrm{~ms}$

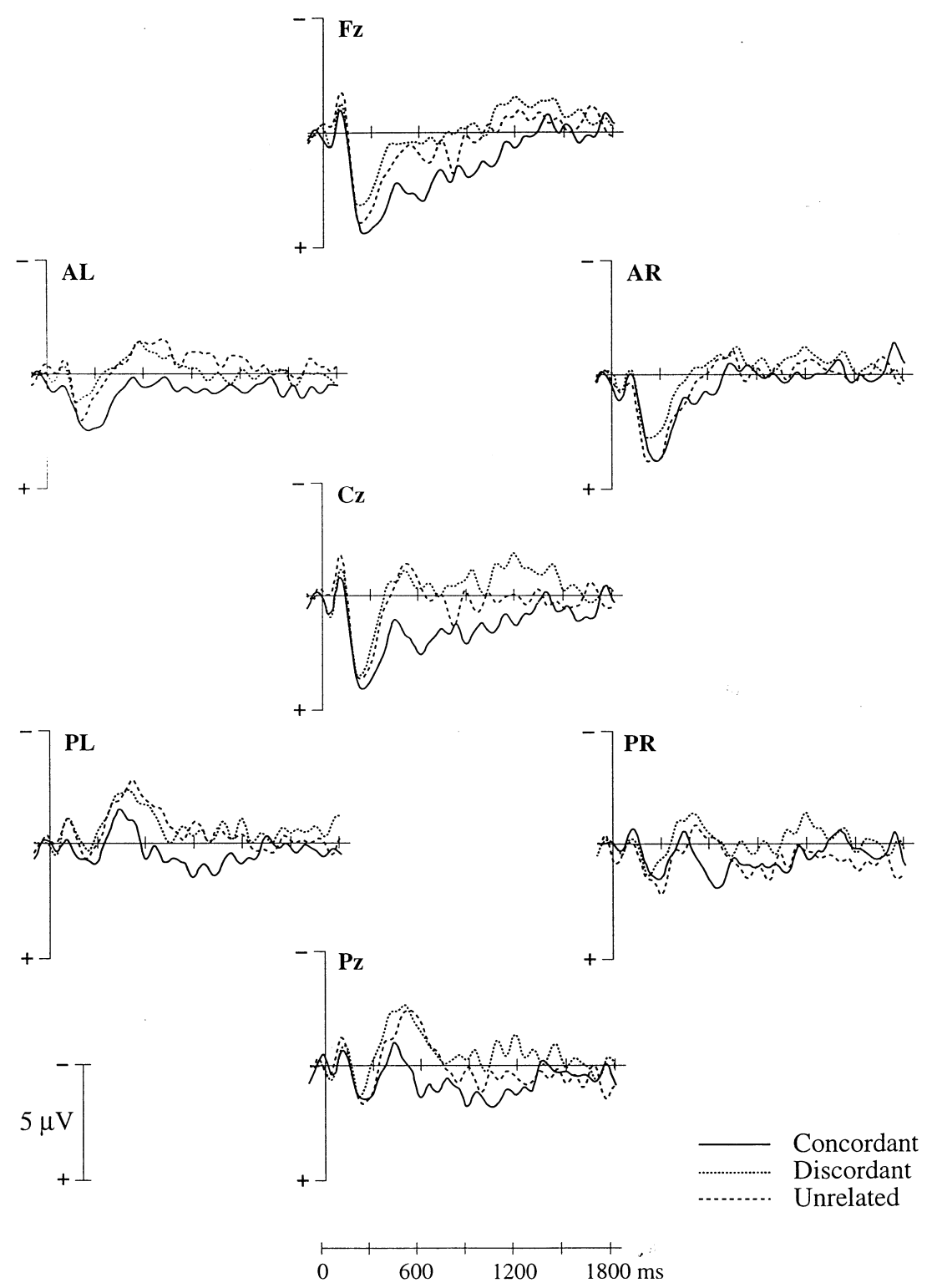

Fig. 7. Grand average ERPs from the Broca's aphasics $(n=12)$ in the long $(1250 \mathrm{~ms})$ ISI version to the targets in the concordant (solid line), discordant (dotted line) and unrelated (dashed line) lexical ambiguity conditions.

$F(1,9)=10.12, \mathrm{MSe}=10.90, P<0.02)$ and between the unrelated and the discordant condition $(\mathrm{U}-\mathrm{D}=-1.18$ $\mu \mathrm{V}, F(1,9)=10.69$, MSe $=3.15, P<0.01)$. The difference between the discordant and the concordant condition did not reach significance (D-C $=-0.96 \mu \mathrm{V}$, $F(1,9)=4.08, \mathrm{MSe}=5.41, P=0.07)$.

Broca's aphasics, $I S I=100$. Figure 5 shows that the $\mathrm{N} 400$ is followed by a positive going deflection, especially for the discordant and the unrelated conditions. In the 600-1000 ms latency range, the difference between the concordant and the discordant conditions is no longer visible and the waveform for the unrelated condition remains more negative than for both the concordant and the discordant conditions.

In the planned comparisons, significant differences were obtained between the unrelated and the concordant condition $\quad(\mathrm{U}-\mathrm{C}=-1.71 \quad \mu \mathrm{V}, \quad F(1,9)=12.20$, $\mathrm{MSe}=5.72, P<0.007)$ and between the unrelated and the discordant condition $(\mathrm{U}-\mathrm{D}=-1.33 \mu \mathrm{V}$, $F(1,9)=10.69$, MSe $=3.98, P<0.01)$, but not between the discordant and concordant condition (D-C $\mu \mathrm{V}=-0.38, F<1$ ).

Normal controls, $I S I=1250$. As can be seen in Fig. 6, in contrast to the $\mathrm{N} 400$, the late positive deflections for 
the normal controls show a clear deviation between the unrelated and the discordant condition, whereas the difference between the concordant and the discordant appears smaller for the late positivities than for the N400.

A significant difference was obtained between the unrelated and the concordant condition (U-C $=-2.02 \mu \mathrm{V}$, $F(1,9)=22.95, \mathrm{MSe}=4.27, P<0.002)$ and between the unrelated and the discordant condition (U-D $=-1.20$ $\mu \mathrm{V}, F(1,9)=11.03, \mathrm{MSe}=3.15, P<0.009)$, but the difference between the discordant and the concordant condition failed to reach significance $(\mathrm{D}-\mathrm{C}=-0.82 \mu \mathrm{V}$, $F(1,9)=4.41, \mathrm{MSe}=3.64, P=0.06)$.

Broca's aphasics, ISI $=1250$. In the $600-1000 \mathrm{~ms}$ window, the concordant condition appears to be more positive than the discordant and the unrelated conditions (Fig. 7), whereas the latter two conditions do not appear to show any systematic differences.

The planned comparisons showed a significant difference between the discordant condition and the concordant condition $(\mathrm{D}-\mathrm{C}=-1.60 \mu \mathrm{V}, F(1,9)=24.31$, $\mathrm{MSe}=2.51, P<0.0001)$. The difference between the unrelated condition and the concordant condition just failed to reach significance $(\mathrm{U}-\mathrm{C}=-1.14 \mu \mathrm{V}$, $F(1,9)=4.44, \mathrm{MSe}=6.71, P=0.06)$, and the difference between the unrelated condition and the discordant condition was not significant either $(\mathrm{U}-\mathrm{D}=+0.46 \mu \mathrm{V}$, $F(1,9)=1.68, \mathrm{MSe}=3.02, P=.23)$.

\section{Analysis of P300 effects}

Artifact rejection and correction procedures were identical to those that were described earlier for the N400, except that for the P300 the whole sampling epoch (1000 $\mathrm{ms}$ ) was screened for artifacts. The overall rejection rate was $21 \%$ for the normal controls, and $9 \%$ for the Broca's aphasics ( $9 \%$ for the high comprehenders and $9 \%$ for the low comprehenders).

Average waveforms were computed for each subject for the 60 randomly selected high tones (standards), and for 60 low tones (oddballs). Repeated measures ANOVAs were done for each subject group separately on the mean amplitude of the P300 in the 250-500 ms epoch after stimulus onset, relative to a $150 \mathrm{~ms}$ pre-stimulus baseline. The factors that entered each analysis were: Subjects, Tone Probability (High vs Low) and Electrode Site (Cz, Pz, PL, PR).

Normal controls. Since one subject was not available for further participation, only 11 subjects were tested in the tone oddball experiment. The average waveforms for these subjects are shown in Fig. 8. This figure shows a large P300 component to the oddball tones, with a characteristic centroparietal distribution. The oddball effect of $5.33 \mu \mathrm{V}$ was highly significant $(F(1,10)=43.01$, $\mathrm{MSe}=14.55, P<0.0002$ ).

Broca's aphasics. Figure 9 presents the average waveforms for the Broca's aphasics. Relative to the normal controls, N1, P2 and P300 components are clearly reduced, but the $\mathrm{P} 300$ has retained its posterior distribution. The oddball effect of $2.43 \mu \mathrm{V}$ failed to reach significance $(F(1,11)=3.63, \mathrm{MSe}=39.18, P=0.08)$.

High vs low comprehenders. In the ANOVA with Group of Subjects as the additional factor, a significant Group of Subjects by Tone Probability interaction was found $(F(1,10)=7.60, \mathrm{MSe}=24.49, P<0.03)$. Therefore, additional ANOVAs were done for the high and the low comprehenders separately. These analyses yielded a significant oddball effect of $5.22 \mu \mathrm{V}$ for the high comprehenders $(F(1,5)=14.64, \mathrm{MSe}=22.33, P<0.02)$, but not for the low comprehenders $(-0.35 \mu \mathrm{V}, F<1)$. The absence of this effect for the low comprehenders was however partly due to individual subject differences (see later).

\section{Individual subject data}

Table 3 shows the results for the individual subject data for the normal controls in the linguistic control conditions, the lexical ambiguity conditions and the tone oddball experiment. In addition, the mean values for the N400 and the P300 are displayed. Table 4 shows the same for the Broca's aphasics and in addition this table summarizes the information on comprehension scores and lesion volume and it indicates which of the patients had a lesion in the temporo-parietal area. This latter information was included because it has been shown that the temporo-parietal junction is crucial to the generation of the P300 effect [44]. The tables also indicate how many low tones the subjects correctly reported in the oddball experiment. Although there was a clear variation in the size of the P300 effect, it was present in most subjects.

All but one of the normal controls showed more negative going waveforms to the low cloze than to the high cloze critical words in mid-sentence position. The subject that showed a deviant more positive going waveform in the low cloze than in the high cloze condition (subject 10) did however have the expected N400 effect in both versions of the lexical ambiguity experiment. Ten of the 11 subjects that were tested in the oddball experiment showed more positive going waveforms to the oddballs than to the standards in the oddball experiment. Subject 10 did not show a clear difference between conditions.

In the short ISI version of the experiment, all elderly controls showed a reduction of the amplitude of the N400 to the targets in the concordant relative to the unrelated condition and eleven showed this difference in the long ISI version. Ten subjects showed a reduction of the N400 amplitude in the concordant relative to the discordant conditions in both ISI versions of the experiment. Finally, seven elderly controls showed a reduction of the discordant relative to the unrelated condition in the short ISI version and eight in the long ISI version. In short, the individual subjects show a relatively similar pattern of results for both ISI versions of the experiment.

Of the Broca's aphasics, nine of the 12 subjects showed 


\section{ELDERLY NORMAL CONTROLS (N=11), Tone Oddball Task}
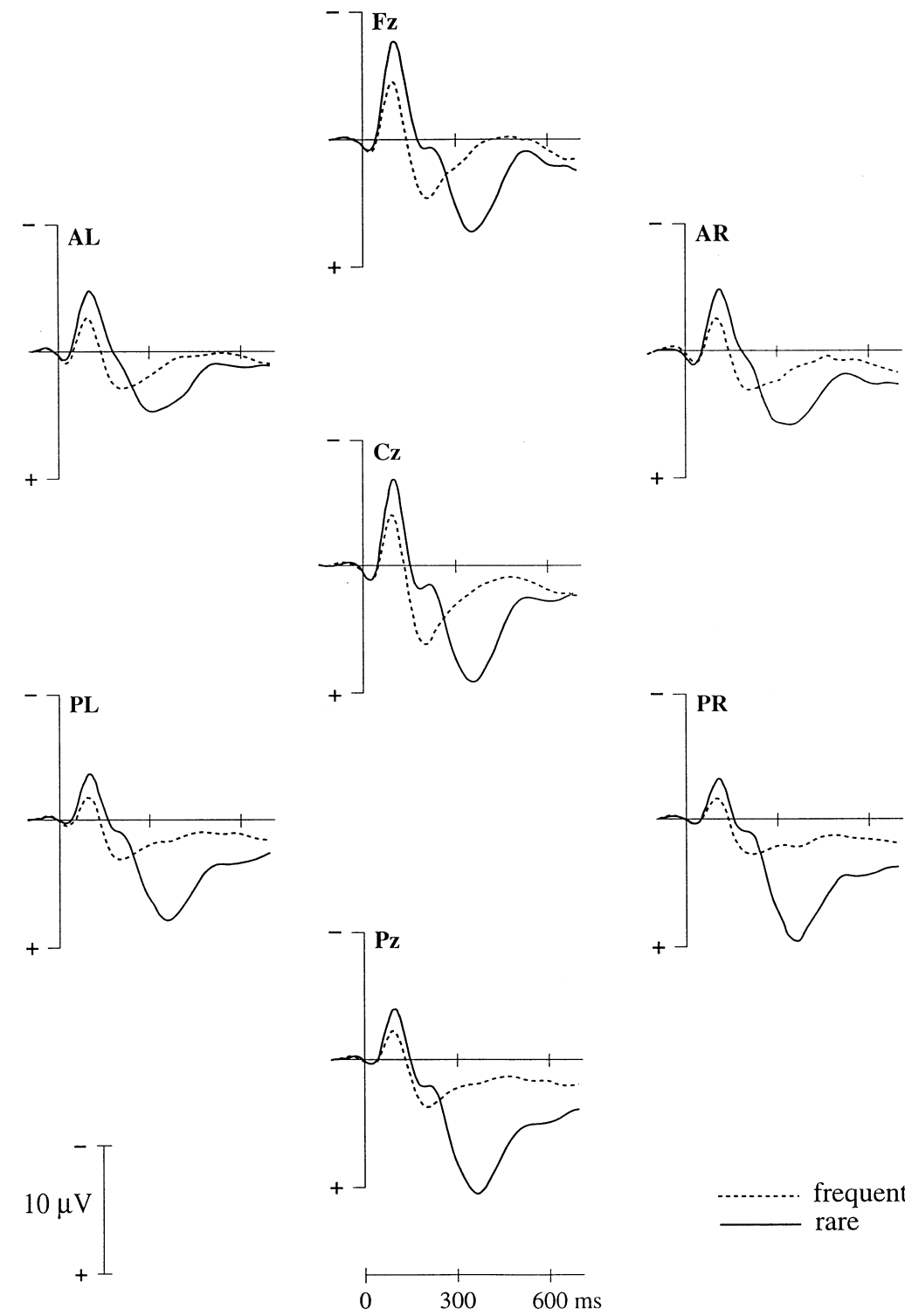

frequent

rare

Fig. 8. Grand average ERPs from the normal controls $(n=11)$ to the frequent (dotted line) and the rare tones (solid line) in the oddball paradigm.

more negative going waveforms to the critical words in the low cloze than in the high cloze condition. Subjects 2, 7 and 9 showed a more positive going waveform to the low cloze than to the high cloze condition. These subjects

* The P300 results of this experiment provide no conclusive evidence with respect to the contribution of the temporo-parietal junction in generating the P300 [44]. Two patients with a lesion in this area $(1,9)$ did show P300 effects and one patient showed the abnormal "reversal" (patient 6). Of the two other patients that showed this "reversal" $(2,11)$, one did not have a lesion in the temporo-parietal junction and of the other one no adequate $\mathrm{CT}$ information was available. were all low comprehenders. The absence of this effect was not correlated with an absence of N400 effects in the ambiguity conditions, because these patients did show N400 effects in at least one version of the contextual selection experiment. Nine patients showed a P300 effect. Three patients (2, 6 and 11, all low comprehenders) showed more negative waveforms to the oddballs than to the standard tones.* As in Hagoort et al. [36] and Swaab et al. [70], this phenomenon seems to be related to the ability to count: Two of the three patients that had a "reversed" oddball effect were unable to count. Two of the three patients that showed this "reversed" oddball 
BROCA'S APHASICS (N=12), Tone Oddball Task
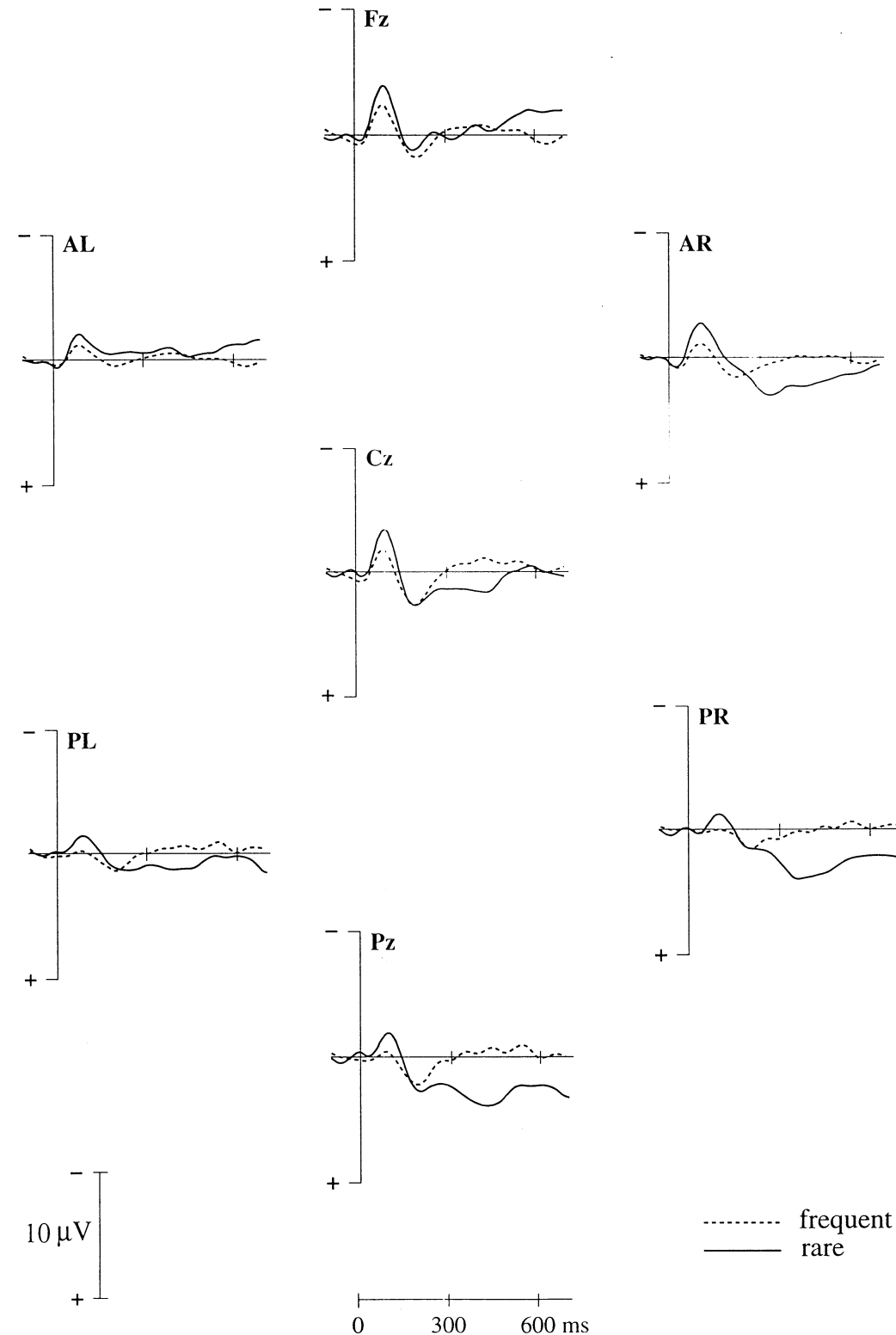

Fig. 9. Grand average ERPs from the Broca's aphasics $(n=12)$ to the frequent (dotted line) and the rare tones (solid line) in the oddball paradigm.

effect did have N400 effects in the linguistic control conditions and all three had N400 effects in the ambiguity conditions of at least one of the ISI versions.

In the short ISI version of the experiment, eleven patients showed a negative difference between the unrelated and the concordant condition and nine showed this in the long ISI version. Most importantly, between the short and the long ISI there is a clear shift from the number of patients who show a reduced N400 amplitude to the targets in the discordant relative to the unrelated condition (from 10 in the short to five in the long ISI version) and there is also a shift in the number of patients who show a reduction of the amplitude to the targets in the concordant relative to the discordant condition (from eight in the short, to all twelve patients in the long ISI version).

In order to determine to what extent the size of the P300 effect was related to the size of the N400 effects in the linguistic control conditions and in the lexical ambiguity conditions, correlations were computed between the N400 effect in the lexical ambiguity conditions of the two ISI versions and the $\mathrm{P} 300$ in the oddball experiment (N400 ambiguity short/P300 and N400 ambiguity long/ $P 300$ ), and between the N400 effect in the control conditions and the P300 effect in the oddball experiment (N400 control/P300), for the normal controls and the 
Table 3. Individual ERP effects of the normal elderly controls for: (1) the two ISI versions of the ambiguity experiment for the unrelated-concordant (U-C), unrelated-discordant (U-D) and discordant-concordant (D-C) comparisons (mean amp in $\mu \mathrm{V}$ in $350-600 \mathrm{~ms}$ area); (2) the high vs low cloze words in mid sentence position (mean amp in $\mu \mathrm{V}$ in $350-600 \mathrm{~ms}$ area); (3) the frequent vs rare tones in the oddball paradigm (mean amp in $\mu \mathrm{V}$ in $250-500 \mathrm{~ms}$ area). The mean ERP effects are displayed in the last row of the table. This table also provides individual subject information on the number of low tones that were counted (correct $=60)$

\begin{tabular}{|c|c|c|c|c|c|c|}
\hline Sjs & $\mathrm{U}-\mathrm{C}$ & U-D & $\mathrm{D}-\mathrm{C}$ & Low-high & P300 & Count low tones \\
\hline \multirow[t]{2}{*}{01} & 100: -6.28 & $100:+0.11$ & 100: -6.39 & -0.91 & +1.61 & 60 \\
\hline & $1250:-4.53$ & $1250:-0.83$ & $1250:-3.70$ & & & \\
\hline \multirow[t]{2}{*}{02} & $100:-3.11$ & $100:-1.66$ & $100:-1.45$ & -0.80 & +7.02 & 61 \\
\hline & $1250:-2.34$ & $1250:-1.41$ & $1250:-0.93$ & & & \\
\hline \multirow[t]{2}{*}{03} & $100:-1.97$ & $100:-1.72$ & $100:-0.25$ & -2.79 & +6.01 & 60 \\
\hline & $1250:-2.82$ & $1250:-0.92$ & $1250:-1.90$ & & & \\
\hline \multirow[t]{2}{*}{04} & $100:-1.63$ & $100:+0.96$ & $100:-2.59$ & -4.40 & +6.10 & 60 \\
\hline & $1250:-2.33$ & $1250:+0.25$ & $1250:-2.58$ & & & \\
\hline \multirow[t]{2}{*}{05} & $100:-0.32$ & $100:+0.08$ & 100: -0.40 & -6.38 & +5.65 & 60 \\
\hline & $1250:-1.13$ & $1250:-0.40$ & $1250:-0.73$ & & & \\
\hline \multirow[t]{2}{*}{06} & 100: -0.07 & $100:+2.24$ & $100:-2.31$ & -2.91 & +3.70 & 60 \\
\hline & $1250:-2.67$ & $1250:+0.80$ & $1250:-3.47$ & & & \\
\hline \multirow[t]{2}{*}{07} & 100: -4.80 & $100:-3.11$ & 100: -1.69 & -1.08 & - & - \\
\hline & $1250:-1.72$ & $1250:-0.31$ & $1250:-1.41$ & & & \\
\hline \multirow[t]{2}{*}{08} & $100:-2.37$ & $100:-2.47$ & $100:+0.10$ & -0.78 & +7.86 & 60 \\
\hline & $1250:-1.51$ & $1250:-0.49$ & $1250:-1.02$ & & & \\
\hline \multirow[t]{2}{*}{09} & $100:-1.38$ & $100:-1.40$ & $100:+0.02$ & -3.11 & +4.86 & 60 \\
\hline & $1250:+0.37$ & $1250:+0.08$ & $1250:+0.29$ & & & \\
\hline \multirow[t]{2}{*}{10} & $100:-1.13$ & $100:+1.41$ & $100:-2.54$ & +0.32 & +0.02 & 60 \\
\hline & $1250:-2.68$ & $1250:-2.02$ & $1250:-0.66$ & & & \\
\hline \multirow[t]{2}{*}{11} & $100:-2.38$ & $100:-1.86$ & $100:-0.52$ & -0.49 & +6.52 & 60 \\
\hline & $1250:-0.71$ & $1250:+1.46$ & $1250:-2.17$ & & & \\
\hline \multirow[t]{2}{*}{12} & $100:-3.18$ & 100: -0.59 & $100:-2.59$ & -0.17 & +9.33 & 60 \\
\hline & $1250:-1.30$ & $1250:-1.66$ & $1250:+0.36$ & & & \\
\hline \multicolumn{7}{|l|}{ Mean } \\
\hline ERP & 100: -2.39 & 100: -0.68 & $100:-1.72$ & -1.96 & +5.33 & \\
\hline Effects & $1250:-1.95$ & $1250:-0.45$ & $1250:-1.49$ & & & \\
\hline
\end{tabular}

patients. For the lexical ambiguity conditions, the values of the N400 effects that were found in the comparison between the unrelated and the concordant condition were entered into these analyses, for the short and the long ISI version of the experiment separately. None of these comparisons yielded a significant correlation ( $N 400 \mathrm{con}$ trol $/ P 300$; normal controls: $r=0.07, P=0.84$, Broca's aphasics: $r=0.10, \quad P=0.76 ; \quad N 400$ ambiguity short ISI/P300; normal controls: $r=0.02, P=0.96$, Broca's aphasics: $\quad r=0.04, \quad P=0.90 ; \quad N 400$ ambiguity long ISI/P300; normal controls: $r=0.50, P=0.12$, Broca's aphasics: $r=0.13, P=0.68)$.

\section{Discussion}

The present study investigated the resolution of lexically ambiguous words in sentence contexts by Broca's aphasics. Previous studies have shown that these patients may be unable to activate the subordinate meaning of ambiguous words [73], or that the time course of the activation of the subordinate meaning is delayed in Broca's aphasics [73]. We argue that the ERP results of the present study are compatible with an alternative hypothesis, namely that Broca's aphasics are delayed in the process of lexical integration [31]. We will now first discuss the results for the control conditions in the language study and the oddball experiment. Then the results of the lexical ambiguity conditions are discussed.

\section{Control results}

Oddball. The results of the oddball experiment of the present study were clearly in line with the findings that were reported by Hagoort et al. [36] and by Swaab et al. [70]. No significant correlation between the P300 and N400 effects was found, which indicates that P300 and N400 effects are functionally independent in the aphasic patients and the neurologically unimpaired subjects in this study. We therefore conclude that the changes in the N400 effects of the aphasic patients relative to their controls most likely reflect aspects of the patients' underlying language deficits, and not an aspecific effect of brain 
Table 4. Individual ERP effects of the Broca's aphasics for: (1) the two ISI versions of the ambiguity experiment for the unrelatedconcordant (U-C), unrelated-discordant (U-D) and discordant-concordant (D-C) comparisons (mean amp in $\mu \mathrm{V}$ in 350-600 ms area); (2) the high vs low cloze words in mid sentence position (mean amp in $\mu \mathrm{V}$ in 350-600 ms area); (3) the frequent vs rare tones in the oddball paradigm (mean amp in $\mu \mathrm{V}$ in 250-500 $\mathrm{ms}$ area). The mean ERP effects are displayed in the last row of the table. This table also provides individual subject information on the number of low tones that were counted (correct $=60$ ), the comprehension scores on the comprehension subtest of the AAT, the lesion volume. The lesion site is marked with a + if it involves the temporoparietal area. Patients with moderate to severe comprehension deficits are indicated with L and patients with light to very mild comprehension deficits are indicated with $\mathrm{H}$

\begin{tabular}{|c|c|c|c|c|c|c|c|c|c|}
\hline Pat. & $\mathrm{U}-\mathrm{C}$ & U-D & $\mathrm{D}-\mathrm{C}$ & Low-high & P300 & $\begin{array}{l}\text { Count low } \\
\text { tones }\end{array}$ & Com sco & Les vol & Les sit \\
\hline \multirow[t]{2}{*}{$01 \mathrm{H}$} & 100: -0.86 & $100:-1.30$ & $100:+0.44$ & -1.21 & +7.90 & 60 & 94 & 60 & + \\
\hline & $1250:-1.34$ & $1250:-0.72$ & $1250:-0.62$ & & & & & & \\
\hline \multirow[t]{2}{*}{$02 \mathrm{~L}$} & 100: -2.00 & 100: -0.56 & $100:-1.44$ & +0.32 & -2.98 & 60 & 67 & 121 & \\
\hline & $1250:-1.85$ & $1250:+0.46$ & $1250:-2.31$ & & & & & & \\
\hline \multirow[t]{2}{*}{$03 \mathrm{H}$} & $100:+1.41$ & $100:+0.50$ & 100: +0.91 & -2.25 & +2.64 & 59 & 105 & 14 & \\
\hline & $1250:+0.53$ & $1250:+0.63$ & $1250:-0.10$ & & & & & & \\
\hline \multirow[t]{2}{*}{$04 \mathrm{~L}$} & $100:-4.67$ & 100: -2.19 & 100: -2.48 & -2.07 & +2.83 & 70 & 74 & 17 & \\
\hline & 1250: -0.79 & $1250:+0.73$ & $1250:-1.52$ & & & & & & \\
\hline \multirow[t]{2}{*}{$05 \mathrm{H}$} & 100: -4.49 & 100: -1.11 & 100: -3.38 & -1.43 & +4.98 & 63 & 97 & - & - \\
\hline & $1250:-3.43$ & $1250:-1.78$ & $1250:-1.65$ & & & & & & \\
\hline \multirow[t]{2}{*}{$06 \mathrm{~L}$} & 100: -1.15 & $100:-0.46$ & 100: -0.69 & -1.15 & -3.28 & NOT & 65 & 73 & + \\
\hline & $1250:+0.95$ & $1250:+2.22$ & 1250: -1.27 & & & & & & \\
\hline \multirow[t]{2}{*}{$07 \mathrm{~L}$} & 100: -3.04 & 100: -3.14 & $100:+0.10$ & +2.07 & +2.94 & NOT & 90 & 105 & \\
\hline & $1250:+0.05$ & $1250:+1.95$ & 1250: -1.90 & & & & & & \\
\hline \multirow[t]{2}{*}{$08 \mathrm{H}$} & 100: -2.02 & $100:-2.58$ & $100:+0.56$ & -1.83 & +10.5 & 60 & 108 & 127 & \\
\hline & $1250:-0.44$ & $1250:+1.27$ & $1250:-1.71$ & & & & & & \\
\hline \multirow[t]{2}{*}{$09 \mathrm{~L}$} & 100: -1.77 & 100: -1.16 & 100: -0.61 & +1.55 & +3.06 & 60 & 65 & 219 & + \\
\hline & $1250:-1.78$ & $1250:+2.15$ & $1250:-3.93$ & & & & & & \\
\hline \multirow[t]{2}{*}{$10 \mathrm{H}$} & $100:-4.35$ & 100: -1.19 & $100:-3.16$ & -4.08 & +3.16 & NOT & 98 & 50 & \\
\hline & $1250:-2.55$ & $1250:-1.48$ & $1250:-1.08$ & & & & & & \\
\hline \multirow[t]{2}{*}{$11 \mathrm{~L}$} & $100:-2.31$ & $100:+0.78$ & 100: -3.09 & -1.75 & -4.66 & NOT & 87 & - & - \\
\hline & 1250: -0.25 & 1250: -0.09 & 1250: -0.16 & & & & & & \\
\hline \multirow[t]{2}{*}{$12 \mathrm{H}$} & 100: -5.97 & 100: -3.45 & $100:-2.52$ & -3.74 & +2.12 & 63 & 93 & 141 & \\
\hline & 1250: -7.10 & 1250: -2.80 & $1250:-4.30$ & & & & & & \\
\hline \multicolumn{10}{|l|}{ Mean } \\
\hline ERP & 100: -2.60 & $100:-1.32$ & $100:-1.28$ & -1.30 & +2.43 & & & & \\
\hline Effects & 1250: -1.50 & $1250:+0.21$ & 1250: -1.71 & & & & & & \\
\hline
\end{tabular}

damage and will interpret our results for the ambiguity conditions accordingly.

\section{Cloze probability}

In the linguistic control conditions, the Broca's aphasics were sensitive to the effect of cloze probability. Interestingly, this effect was apparently influenced by the severity of their comprehension deficit. While the high comprehenders showed a clear N400 effect of cloze probability that was comparable in size to that of the normal controls, this effect was not observed for the low comprehenders. This finding is in accordance with the findings of Swaab et al. [70]. Compared to a group of normal elderly control subjects, a delay in the N400 effect to sentence-final anomalous vs sentence-final congruent words was found for a group of low comprehenders. This

* Importantly, these same patients were able to generate an N400 effect, as was evident from their results in the ambiguity conditions. delay was absent for a group of high comprehenders. Swaab et al. [70] argued that the delay in the N400 effect for the low comprehenders reflects a delay in the integration of lexical information into a higher order representation of the preceding sentence context. If low comprehenders indeed suffer from a delay in lexical integration, then this may have resulted in an incomplete or degraded context representation in these patients. Relative to this incomplete or degraded context representation, there may be no effective difference in the meaning match for high and low cloze words, which could explain the absence of their N400 effect in this control study.*

\section{Lexical ambiguity results}

Before discussing the results of the ambiguity conditions we would first like to address a possible concern that could be raised with respect to the repetition of the stimuli over the ISI versions of the experiment. Repetition of words has been observed to reduce the amplitude of the N400 and increase the amplitude of a late positive 
component $[65,71]$. This pattern of results was not obtained for the normals in the current experiment, where no change in the size of any of the effects was found in the N400 window nor in the 600-1000 ms window where the positive deflections were observed. For the Broca's aphasics, one significant change was found between the short and the long ISI versions of the experiment: In the short ISI version the difference between unrelated and discordant was significant for the N400 and for the 600 $1000 \mathrm{~ms}$ window, but this was not the case in either of these windows in the long ISI version of the experiment. This change is not easily explained in terms of repetition either, because it was specific to one comparison and not found for the others. Since all the conditions were repeated to the same degree, it is not very likely that only one condition would vary with repetition. We therefore maintain that the pattern of results that was found for the normal controls and the aphasic patients in this study cannot be attributed to the effects of repetition.

\section{N400 to targets}

In this experiment on the time course of ambiguity resolution, the selection of the contextually appropriate meaning is a by-product of the process of lexical integration. Hypothetically the contextually appropriate and the contextually inappropriate meanings are activated and matched rapidly against the context. For the inappropriate meaning the match is unsuccessful and this meaning is not integrated, resulting in its decay or suppression. But for the contextually appropriate meaning, the match against the context is successful and this meaning can be integrated into the higher order representation of the preceding context.

With respect to the resolution of lexically ambiguous words in sentence contexts, it was clear that the normal control subjects had accessed the contextually appropriate subordinate meaning in both ISI versions. This is evident from the reduction of the amplitude of the N400 to the targets in the concordant relative to the unrelated and the discordant conditions. Furthermore, the elderly

* An additional ANOVA was done that directly compared the N400 effects (i.e. the difference waveforms) for the crucial conditions, namely the unrelated condition and the discordant condition, for the normals and the Broca's aphasics over the ISI's, with a Group of Subjects as the additional factor. Although in the expected direction, the interaction between Group of Subjects and ISI did not quite reach significance $(F(1,44)=2.57, \mathrm{MSe}=8.13, P=0.11)$. However, the most crucial finding of this article was that the normal controls did not show any activation of the contextually irrelevant meaning of the ambiguous word in either of the ISI versions of the experiment. The Broca's aphasics on the other hand showed a significant change in the activation of the contextually inappropriate meaning between the ISI versions of the experiment: This meaning was active in the short but not in the long ISI version of the experiment. controls did not show a significant difference in the amplitude of the $\mathrm{N} 400$ between the discordant and the unrelated conditions in either of the ISI versions, which suggests that the subordinate meaning had decayed or was suppressed when it was contextually inappropriate. In addition, no significant differences were found between the N400 pattern of results in the short and the long ISI versions of the experiment. These data show that the elderly controls had completed the process of contextually guided lexical selection in a relatively short period of time.

In the short ISI version of the experiment, the group of Broca's aphasics also showed clear evidence that they had accessed the subordinate meaning when it was contextually appropriate: The amplitude of the N400 to the targets in the concordant condition was significantly reduced relative to the unrelated targets. However, in contrast to the normal controls, the Broca's aphasics showed a significant difference between the unrelated and the discordant conditions. This indicates that these patients had not completed the contextual selection process $100 \mathrm{~ms}$ after the offset of the sentence final ambiguous word. But in the long ISI version of the experiment, the Broca's aphasics did show evidence of contextual selection: They had integrated the contextually appropriate meaning and the contextually inappropriate meaning had decayed or was suppressed. This contrast between the short and the long ISI versions of the experiment was substantiated by the fact that a significant difference was found in the size of the N400 effect for the unrelated minus discordant conditions between the two ISI versions. The pattern of results is also supported by the individual subject data. In the short ISI version, there were eight patients who showed a negative difference between the discordant and the concordant condition, while all subjects showed this difference at the long ISI. On the other hand, there were 10 patients who showed a negative difference between the unrelated and the discordant condition at the short ISI, while only five subjects showed this difference at the long ISI. It seems therefore reasonable to conclude that Broca's aphasics are able to use the sentence context to integrate the contextually appropriate meaning. But in addition, these patients appear to be delayed in the process of contextual selection/ integration: The contextually inappropriate meaning had not decayed or was not yet suppressed in the short ISI version of the experiment.*

In comparison with the results of Hagoort et al. [36] and Swaab et al. [70], and with the linguistic control conditions of the present study, it is noteworthy to find that the delay in contextual selection is not limited to the group of low comprehenders, but that it was also found in the group of high comprehenders. A possible explanation for the absence of a difference in the pattern of results for the low and the high comprehenders is that the timing conditions of the present experiment were not sensitive enough to detect these differences. It might well be the case that the high comprehenders are faster in 
selecting the contextually appropriate meaning than the low comprehenders and that this would have become apparent if the activational status of the sentence-final ambiguity had been probed at an ISI between 100 and $1250 \mathrm{~ms}$.

\section{Late positivities}

For the normal controls there was initially no difference between the discordant and the unrelated condition in either ISI version of the experiment, but a difference did emerge for the late positive deflections in both ISI versions (see Figs 4 and 6, respectively). This result indicates that after initial selection of the contextually appropriate meaning, the contextually inappropriate meaning became (re-) activated. Although we had no a priori predictions with respect to these late positivities, we will discuss a possible account for the pattern of results in terms of working memory capacity. It may be the case that the normal controls had enough working memory capacity to retain the sentence final ambiguous word so that they could integrate the contextually appropriate meaning and have the additional realization that the unintegrated inappropriate meaning of the ambiguous word has a meaning relation with the target word in the discordant condition. In this scenario the difference in the 600-1000 ms window between the discordant relative to the unrelated condition could occur because the subjects had made a semantic (backward) match between the target and the sentence-final ambiguous word in the discordant condition, even in the long ISI version of the experiment.

In the $600-1000 \mathrm{~ms}$ window of the late positivities, the Broca's aphasics showed no difference in the activation of the contextually appropriate and the contextually inappropriate meaning in the short ISI version of the experiment. In the long ISI version, however, there was no evidence of activation of the contextually inappropriate meaning. This differential pattern between the long and the short ISI may reflect a working memory capacity limitation for the Broca's aphasics. In the long ISI version of the experiment, these patients may have been unable to keep the ambiguous sentence final word in memory long enough to appreciate its relationship with the target in the discordant context.

Although these late effects are intriguing, they do not represent the main focus of this article. For the purposes of the present experiment the most relevant result is that the normal controls showed evidence of contextual selection in the short ISI version of the experiment, but that the Broca's aphasics needed more time to complete this process of contextual selection.

\section{Conclusions}

In conclusion, the overall pattern of results of the present study is at odds with the idea that Broca's aphasics are unable to exhaustively access multiple meanings of ambiguous words [73]. The current study clearly shows that Broca's aphasics have integrated the subordinate meaning into the higher order representation of the preceding sentence context and therefore, they must have accessed this meaning as well. Thus the present data support the alternative idea that Broca's aphasics are delayed in the process of contextual selection. Several mechanisms may underlie this delayed contextual selection process.

First, Broca's aphasia may lead to a delay in the activation of lexical meanings. The process of contextual selection depends on the fast access to and integration of the activated lexical meanings into the higher order representation of the preceding sentence context. Given the fact that the activational status of the sentence-final ambiguities was probed at a $100 \mathrm{~ms}$ after the offset of these words, the current results cannot exclude the possibility of a delay in the activation of lexical meanings in the Broca's aphasics [73]. But at $100 \mathrm{~ms}$ after the offset of the ambiguous word, clear activation of the subordinate meaning was evident from the reduction of the N400 to the targets in the concordant relative to the unrelated and the discordant conditions. This indicates that $100 \mathrm{~ms}$ after the offset of the lexically ambiguous word, lexical meanings were sufficiently activated to enter into the contextual selection process for the appropriate meaning. The selection process, however, had not been completed within this time frame. Therefore, a slower than normal rise time for the activation of lexical meanings does not provide a sufficient explanation for the delay in contextual selection that was observed for the Broca's aphasics in the present study.

Alternatively, one may argue that the pattern of results that was obtained for the Broca's aphasics in this study can be explained in terms of delayed suppression. A delay in suppression has been proposed to explain activation of the contextually irrelevant meaning of ambiguous words at long delays in normal but less skilled readers $[22,23]$. Our study was done in the auditory modality, but it may very well be that a suppression mechanism is also involved in the selection of the contextually appropriate meaning when speech is processed. On the basis of the results of our current study, we cannot exclude the idea that a delay in suppression plays a role in the spoken comprehension deficits in Broca's aphasics, since in the absence of a neutral condition we cannot distinguish between activation and inhibition processes. However, there are a number of reasons that lead us to assume that a delay in suppression was not the major factor underlying the results of the present study. Unlike the less skilled readers in the Gernsbacher and Faust study [22], the Broca's aphasics in our study did not show any evidence of activation of the contextually inappropriate meaning in the long ISI version of the experiment. Furthermore, Long et al. [51] have recently shown that the delayed suppression of contextually irrelevant meanings in neurologically normal but less skilled readers is only 
obtained when these subjects are engaged in tasks that require overt checking of the context, such as a semantic judgement task. Because the subjects in our study had no task other than to listen attentively to the sentences and the target words that followed them, a delay in suppression is not necessarily expected to occur. And finally, in a number of studies it was found that Broca's aphasics show normal priming effects at short SOA'S, which is difficult to explain in terms of a delay in suppression [32, 33].

We propose therefore, that the delay in contextual selection in Broca's aphasics reflects a delay in the process of lexical integration, because the process of contextual selection is dependent upon normal integration of the meaning of words into the preceding context. If the integration process is delayed, then this will delay or affect the construction of an overall sentence meaning representation, which will impair normal sentence comprehension.

The idea that comprehension deficits in Broca's aphasia might result from a delay in the process of lexical integration is supported by the results of a number of recent studies in Broca's aphasics [32, 33, 36, 70] and fits with the idea that the left hemisphere is especially well suited for quick contextual selection and integration processes $[7,10,18]$. Further studies may illuminate the nature of this integration deficit and should establish the extent of the delay in lexical integration in Broca's aphasia in more detail.

Acknowledgements - This research was performed at the Max Planck Institute for Psycholinguistics, within the "Neurocognition of Language Processing" research group, and was supported by grants 560-264-040 and 400-56-384 from the Netherlands Organization of Scientific Research (NWO). T.S. was supported by a fellowship of the James S. McDonnell Foundation during the writing of this article. We are grateful to Peter Praamstra and Mariken ter Keurs for providing and transcribing CT/MRI scans, to Inge Tarim and Clay Clayworth for making the Figures, to Hanneke Wentink and Annemieke Nevejan for testing the patients with the AAT and to René de Bruin and Clif Kussmaul for technical support. We would also like to thank Bob Knight and Michael Gazzaniga for their advice and support and Ron Mangun and two anonymous reviewers for their helpful comments on a previous version of this manuscript.

\section{References}

1. Allison, T., Wood, C. C. and McCarthy, G. M., The central nervous system. In Psychophysiology: systems, processes and applications. eds M. G. M. Coles, E. Donchin and S. W. Porges. Guilford, New York, 1986.

2. Basso, A., Lecours, A. R., Moraschini, S. and Vanier, M., Anatomoclinical correlations of the aphasias as defined through computerized tomography: Exceptions. Brain \& Language, 1985, 26, 201-229.

3. Bates, E., Friederici, A. and Wulfeck, B., Gram- matical morphology in aphasia: Evidence from three languages. Cortex, 1987, 2, 545-574.

4. Besson, M. and Macar, F., An event-related potential analysis of incongruity in music and other nonlinguistic contexts. Psychophysiology, 1987, 24, 14 25.

5. Brown, C. M. and Hagoort, P., The processing nature of the N400: evidence from masked priming. Journal of Cognitive Neuroscience, 1993, 5, 34-44.

6. Brown, C., Hagoort, P. and Swaab, T. Y., Neurophysiological evidence for a temporal disorganization in aphasic patients with comprehension deficits. In Aphasietherapie im Wandel, eds W. Widdig, I. Ohlendorff and J. P. Malin. Hochschul Verlag, Freiburg, 1997.

7. Burgess, C. and Simpson, G. B., Cerebral hemispheric mechanisms in the retrieval of ambiguous word meanings. Brain \& Language, 1988, 33, 86-103.

8. Caplan, D. and Hildebrandt, N., Disorders of syntactic comprehension. MIT Press, Cambridge, MA, 1988.

9. Caramazza, A. and Zurif, E. B., Dissociation of algorithmic and heuristic processes in language comprehension: Evidence from aphasia. Brain and Language, 1976, 3, 572-582.

10. Chiarello, C., Richards, L. and Pollock, A., Semantic additivity and semantic inhibition: Dissociable processes in the cerebral hemispheres? Brain \& Language, 1992, 42, 52-76.

11. Chwilla, D. J. Electrophysiology of word processing: The lexical nature of the N400 priming effect. Doctoral Dissertation. Koninklijke Wöhrman, Zutphen, 1996.

12. Chwilla, D. J., Brown, C. M. and Hagoort. P., The N400 as a function of the level of processing. Psychophysiology, 1995, 32, 274-285.

13. Conrad C., Context effects in sentence comprehension: A study of the subjective lexicon. Memory and Cognition, 1974, 2, 130-138.

14. Donchin, E., Surprise...Surprise? Psychophysiology, 1981, 18, 493-513.

15. Dopkins, S., Morris, R. K. and Rayner, K., Lexical ambiguity and eye fixations in reading: A test of competing models of lexical ambiguity resolution. Journal of Memory and Language, 1992, 31, 461-476.

16. Dronkers, N. F., Shapiro, J. K., Redfern, B. and Knight R. T., The role of Broca's area in Broca's aphasia. Journal of Clinical and Experimental Neuropsychology, 1992, 14, 52-53.

17. Duffy, S. A., Morris, R. K. and Rayner, K., Lexical ambiguity and fixation times in reading. Journal of Memory and Language, 1988, 27, 429-446.

18. Faust, M. E. and Gernsbacher, M. A., Cerebral mechanisms for suppression of inappropriate information during sentence comprehension. Brain \& Language, 1996, 53, 234-259.

19. Friederici, A. D., The time course of syntactic activation during language processing: A model based on neuropsychological and neurophysiological data. Brain and Language, 1995, 50, 259-281.

20. Friederici, A. D. and Kilborn, K. Temporal constraints on language processing: Syntactic priming in Broca's aphasia. Journal of Cognitive Neuroscience, 1989, 1, 262-272. 
21. Friederici, A. D., Pfeifer, E., Hahne, A., Eventrelated brain potentials during natural speech processing: Effects of semantic, morphological and syntactic violations. Cognitive Brain Research, 1993, 1, 183-192.

22. Gernsbacher, M. A. and Faust, M. E., The mechanism of suppression: A component of general comprehension skill. Journal of Experimental Psychology: Learning, Memory and Cognition, 1991, 17, 245-262.

23. Gernsbacher, M. A. and Robertson, R. R. W., Reading skill and suppression revisited. Psychological Science, 1995, 6, 165-169.

24. Glucksberg, S., Kreuz, R. J. and Rho, S. H., Context can constrain lexical access: Implications for models of language comprehension. Journal of Experimental Psychology: Learning, Memory and Cognition, 1986, 12, 323-335.

25. Goodglass, H. and Baker, E., Semantic field, naming, and auditory comprehension in aphasia. Brain and Language, 1976, 3, 359-374.

26. Graetz, P., De Bleser, R. and Willmes, K., Akense Afasie Test. Swets \& Zeitlinger, Lisse, 1992.

27. Gratton, G, Coles, M. G. H. and Donchin, E., (1983). A new method for off-line removal of ocular artifact. Electroencephalography and Clinical Neurophysiology, 1983, 55, 468-484.

28. Greenhouse, S. W. and Geisser, S., On methods in the analysis of profile data. Psychometrika, 1959, 24, 95-112.

29. Grodzinsky, Y., Agrammatic comprehension of relative clauses. Brain \& Language, 1989, 37, 480-499.

30. Haarmann, H. J. and Kolk, H. H. J., On-line sensitivity to subject-verb agreement violations in Broca's aphasia: The role of syntactic complexity and time. Brain and Language, 1994, 46, 493-516.

31. Hagoort, P., Tracking the time course of language understanding in aphasia. Published doctoral dissertation, Nijmegen University, 1990.

32. Hagoort, P., Impairments of lexical-semantic processing in aphasia: Evidence from the processing of lexical ambiguities. Brain and Language, 1993, 45, 189-232.

33. Hagoort, P., Semantic priming in Broca's aphasics at a short SOA: No support for an automatic access deficit. Brain and Language, 1997, 56, 287-300.

34. Hagoort, P. and Brown, C. M., Brain responses to lexical ambiguity resolution and parsing. In Perspectives on sentence processing, eds C. Clifton, L. Frazier and K. Rayner. Lawrence Erlbaum Associates, Hillsdale, N. J., 1994.

35. Hagoort, P., Brown, C. M. and Groothusen, J., The syntactic positive shift (SPS) as an ERP measure of syntactic processing. Language and Cognitive Processes, 1993, 8, 439-483.

36. Hagoort, P, Brown, C. M. and Swaab, T. Y., Lexicalsemantic event-related potential effects in patients with left hemisphere lesions and aphasia and patients with right hemisphere lesions without aphasia. Brain, 1996, 119, 627-649.

37. Hogaboam, T. W. and Perfetti, C. A., Lexical ambiguity and sentence comprehension. Journal of Verbal Learning and Verbal Behavior, 1975, 14, 265-274.

38. Holcomb, P. J., Semantic priming and stimulus degradation: Implications for the role of the N400 in language processing. Psychophysiology, 1993, 30, 4761.

39. Holcomb, P. J. and Neville, H. J., Natural speech processing: An analysis using event-related brain potentials. Psychobiology, 1991, 19, 286-300.

40. Jasper. H. H., Report to the committee on methods and clinical examination in electroencephalography. Appendix: The ten-twenty system of the International Federation. Electroencephalography and Clinical Neuropsychology, 1959, 10, 371-375.

41. King, J. W. and Kutas, M., Who did what and when? Using word- and clause-level ERPs to monitor working memory usage in reading. Journal of Cognitive Neuroscience, 1995, 7, 376-395.

42. Knight, R. T., Hillyard, S. A., Woods, D. L. and Neville, H., The effects of frontal and temporal parietal lesions on the auditory evoked potentials in man. Electroencephalography and Clinical Neurophysiology, 1980, 50, 112-124.

43. Knight, R. T., Scabini, D., Woods, D. L. and Clayworth, C. C., The effects of lesions of superior temporal gyrus and inferior parietal lobe on temporal and vertex components of the human AEP. Electroencephalography and Clinical Neurophysiology, 1988, 70, 499-509.

44. Knight, R. T., Scabini, D., Woods, D. L. and Clayworth, C. C., Contributions of the temporal-parietal junction to the human auditory P3. Brain Research, 1989, 502, 109-116.

45. Kolk, H., Disorders of syntax in aphasia. Linguisticdescriptive and processing approaches. In The Handbook of Neurolinguistics, eds B. Stemmer and H. A. Whitaker. In press.

46. Kolk, H. and Weijts, M., Judgments of semantic anomaly in agrammatic patients: Argument movement, syntactic complexity, and the use of heuristics. Brain \& Language, 1996, 54, 86-135.

47. Kutas, M. and Hillyard, S. A., Reading senseless sentences: Brain potentials reflect semantic incongruity. Science, 1980, 207, 203-205.

48. Kutas, M. and Hillyard, S. A., Event-related brain potentials to grammatical errors and semantic anomalies. Memory and Cognition, 1983, 11, 539-550.

49. Kutas, M., Lindamood, T. E. and Hillyard, S. A., Word expectancy and event-related brain potentials during sentence processing. In Preparatory and states and processes, eds S. Kornblum and J. Requin. Erlbaum, Hillsdale, NJ, 1984.

50. Kutas, M. and Van Petten, C., Psycholinguistics electrified: Event-related brain potential investigations. In Handbook of psycholinguistics, ed. M. A. Gernsbacher. Academic Press, San Diego, CA, 1994.

51. Long. D. L., Seely, M. R. and Oppy, B. J., A resource limitation account of less skilled readers' suppression problems. Paper presented at the annual Psychonomics Meeting, 1996.

52. Lucas, M., Frequency effects on the processing of ambiguous words in sentence contexts. Language and Speech, 1987, 30, 25-46.

53. Milberg, W., Blumstein, S. E. and Dworetzky, B., Processing of lexical ambiguities in aphasia. Brain and Language, 1987, 31, 138-150. 
54. Milberg, W., Blumstein, S., Katz, D., Gershberg, F. and Brown, T., Semantic facilitation in aphasia: Effects of time and expectancy. Journal of Cognitive Neuroscience, 1995, 7, 33-50.

55. Münte, T. F., Heinze, H-J. and Mangun, G. R. M., Dissociation of brain activity related to syntactic and semantic aspects of language. Journal of Cognitive Neuroscience, 1993, 5, 335-344.

56. Oden, G. C. and Spira, J. L., Influence of context on the activation and selection of ambiguous word senses. Quarterly Journal of Experimental Psychology, 1983, 35A, 51-64.

57. Oldfield, R. C., The assessment of the analysis of handedness: The Edinburgh inventory. Neuropsychologia, 1971, 9, 97-113.

58. Onifer, W. and Swinney, D. A., Accessing lexical ambiguities during sentence comprehension: Effects of frequency of meaning and contextual bias. Memory and Cognition, 1981, 9, 225-236.

59. Osterhout, L. and Holcomb, P. J., Event-related brain potentials elicited by syntactic anomaly. Journal of Memory and Language, 1992, 31, 785-806.

60. Osterhout, L. and Holcomb, P. J., Event-related potentials and language comprehension. In Electrophysiology of mind: Event-related brain potentials and cognition, eds M. D. Rugg and M. G. H. Coles. Oxford University Press, 1995.

61. Prather, P. A., Love, T., Finkel, L. and Zurif, E. B., Effects of slowed processing on lexical activation: Automaticity without encapsulation. Brain and Language, 1994, 47, 326-329.

62. Rayner, K. and Frazier, L., Selection mechanisms in reading lexically ambiguous words. Journal of Experimental Psychology: Learning, Memory and Cognition, 1989, 15, 779-790.

63. Rayner, K., Pacht, J. M. and Duffy, S. A., Effects of prior encounter and global discourse bias on the processing of lexically ambiguous words: Evidence from eye fixations. Journal of Memory and Language, 1994, 33, 527-544.

64. Rugg, M. D., Furda, J. and Lorist, M., The effects of task on the modulation of event-related potentials by word repetition. Psychophysiology, 1988, 25, 5563.

65. Rugg, M. D. and Nagy, M. E., Event-related potentials and recognition memory for words. Electroencephalography \& Clinical Neurophysiology, 1989, 72, 395-406.

66. Seldenberg, M. S., Tanenhaus, M. K., Leiman, J. M. and Bienkowski, M., Automatic access of the meanings of ambiguous words in context: Some limitations of knowledge based processing. Cognitive Psychology, 1982, 14, 489-537.

67. Sereno, S. C., Resolution of lexical ambiguity: Evidence from an eye movement priming paradigm. Journal of Experimental Psychology: Learning, Memory and Behavior, 1995, 21, 582-595.

68. Simpson, G., Meaning dominance and semantic con- text in the processing of lexical ambiguity. Journal of Verbal Learning and Verbal Behavior, 1981, 20, 120 136.

69. Simpson, G., Context and the processing of ambiguous words. In Handbook of Psycholinguistics, ed. M. A. Gernsbacher. Academic Press, San Diego, 1994.

70. Swaab, T. Y., Brown. C. M. and Hagoort, P., Spoken sentence comprehension in aphasia: Event-related potential evidence for a lexical integration deficit. Journal of Cognitive Neuroscience, 1997, 9, 39-66.

71. Swick, D. and Knight, R. T., Event-related potentials differentiate the effects of aging on word and nonword repetition in explicit and implicit memory tasks. Journal of Experimental Psychology: Learning, Memory and Cognition, 1997, 23, 123-142.

72. Swinney, D. A., Lexical access during sentence comprehension: (Re)consideration of context effects. Journal of Verbal Learning and Verbal Behavior, 1979, 18, 645-659.

73. Swinney, D. A., Zurif, E. and Nicol, J. The effects of focal brain damage on sentence processing: An examination of the neurological organization of a mental module. Journal of Cognitive Neuroscience, 1989, 1, 25-37.

74. Tabossi, P., Accessing lexical ambiguity in different types of sentential contexts. Journal of Memory and Language, 1988, 27, 324-340.

75. Tabossi, P., Colombo, L. and Job, R., Accessing lexical ambiguity: Effects of context and dominance. Biological Research, 1987, 49, 161-167.

76. Tabossi, P. and Zardon, F., Processing ambiguous words in context. Journal of Memory and Language, 1993, 32, 359-372.

77. Tyler, L. K., Ostrin, R. K., Cooke, M. and Moss, H. E., Automatic access of lexical information in Broca's aphasics: Against the automaticity hypothesis. Brain \& Language, 1995, 48, 131-162.

78. Van Petten, C. and Kutas, M. Ambiguous words in context: An event-related potential analysis of the time course of meaning activation. Journal of Memory and Language, 1987, 26, 188-208.

79. Van Petten, C. and Kutas, M., Interactions between sentence context and word frequency in event-related brain potentials. Memory and Cognition, 1990, 18, 380-393.

80. Van Petten, C. and Kutas, M. Influences of semantic and syntactic context on open- and closed-class words. Memory and Cognition, 1991, 19, 95-112.

81. Winer, B. J., Statistical principles in experimental design. McGraw-Hill, New York, 1971.

82. Zurif, E. B., Caramazza, A. Myerson, R. and Galvin J., Semantic feature representations for normal and aphasic language. Brain and Language, 1974, 1, 167187.

83. Zurif, E., Swinney, D., Prather, P., Solomon, J. and Bushell, C., An on-line analysis of syntactic processing in Broca's and Wernicke's aphasia. Brain \& Language, 1993, 45, 448-464. 